\title{
A Novel Installation Parameter Optimization Design Method of Forming Tool for Screw Rotor
}

\author{
Zongmin Liu ( $\square$ liu_zm@ctbu.edu.cn ) \\ Chongqing Technology and Business University \\ Jirui Wang \\ Qian Tang \\ Ning Liu \\ https://orcid.org/0000-0002-8517-0652 \\ Bin Xing
}

\section{Research Article}

Keywords: screw rotor, forming tool, cutting performance, design method

Posted Date: February 7th, 2022

DOI: https://doi.org/10.21203/rs.3.rs-1308630/v1

License: (c) (i) This work is licensed under a Creative Commons Attribution 4.0 International License.

Read Full License 


\title{
Forming Tool for Screw Rotor
}

\author{
Zongmin Liu 1,2,5, Jirui Wang 2, Qian Tang ${ }^{3}$, Ning Liu ${ }^{4, *}$, Bin Xing 5*
}

1 National Research Base of Intelligent Manufacturing, Chongqing Technology and Business University, Chongqing 40006.

2 School of Mechanical Engineering, Chongqing Technology and Business University, Chongqing 400067.

3 School of Mechanical and Vehicle Engineering, Chongqing University, Chongqing 400067.

4 Virtual Manufacturing Group, Smart Manufacturing Division, Advanced Remanufacturing and Technology Centre, 3 Cleantech Loop, \#01-01, CleanTech Two, Singapore 637143.

5 Chongqing Industrial Big Data Innovation Center Co. LTD, Chongqing 400067.

* $\quad$ Correspondence: Liu_Ning@artc.a-star.edu.sg; Tel.: +65-96517567

Correspondence: Xing.bin@hotmail.com; Tel.: +86-18601118819

\section{Abstract}

Characterized by a complex contour profile involving arc, cycloid and involute, etc., the screw rotor is usually manufactured by a forming tool. The finished surface quality and efficiency of the screw rotor are determined by the cutting performance of the forming tool. However, the machining performance of the forming tool is closely related to the structure shape of cutting edge, which is then determined by the installation parameters of the forming tool. Therefore, to make the cutting performance of forming tool controllable, it is essential investigate the relationship between the cutting performance of the forming tool and its installation parameters at the design stage. In this paper, a novel installation parameter optimization design method of forming tool for screw rotor is presented. A parametric optimization program is designed to finalize the range of installation parameters satisfying the spatial meshing relation and machining equipment parameters. The profile characteristics of forming tool under different center distances and mounting angles have been investigated. For validation, several screw rotors were ground in experiments and the resulted profile errors were analyzed. The results show that the cost of precision grinding of screw rotor can be significantly reduced, without compromise of machining quality. As such, the proposed design method could serve as a promising platform to faciliate screw rotor manufacture.

Keywords: screw rotor; forming tool; cutting performance; design method

\section{Introduction}

The screw rotor is the core component of screw machinery (e.g., screw pump/compressor/vacuum pump/expander), and its manufacturing accuracy has a direct influence on the comprehensive performance of screw machinery [1]. Undesired profile errors will lead to a wide series of degraded performance including poor sealing, excessive noise and vibration, and reduced wear resistance. Therefore, in real production, the tooth profile accuracy of the screw rotor is required to be extremely high. As such, forming processing has become the most commonly used processing method in screw rotor manufacture, due to its controllable processing accuracy and convenience in rotor profile modification. The mounting parameters of the forming tool can directly determine the attitude of the spatial contact line between the forming tool and the screw rotor, thus further affect the cutting performance of the forming tool. Therefore, to obtain reasonable mounting parameters 
becomes the prerequisite in the design of forming tool. Unfortunately, in traditional screw rotor forming tool design, the mounting parameters are usually obtained by empirical methods. Such methods often lead to poor cutting performance of the forming tool, which will further affect the machining accuracy and efficiency in screw rotor manufacture. In order to achieve robust manufacture of screw rotor, it is essential to optimize the cutting performance of the forming tool by selecting appropriate mounting parameters.

The design principle and method of forming tools for screw rotors have been described in detail in previous literatures [2,3]. These studies have provided the solution method and the solution step of the screw rotor forming tool profile, and valuable references for the design of screw rotor forming tools are provided. However, unfortunately, there is still a lack in the screw rotor forming tool mounting parameter decision method. Tang et al. [4] proposed a new method of screw rotor forming tool design, which avoids the technical difficulty of discontinuous one-medium derivative of screw rotor profile curve. Wu et al. [5], proposed a radial ray method to design the screw rotor forming grinding wheel. This method firstly solved the forming sand profile from the given screw rotor profile, and then figured out the screw rotor profile from the forming wheel profile, thus realizing the screw rotor profile precision forming grinding simulation. Li [6] proposed a novel calculation process based on the end milling cutter spiral groove machining principle to compute the grinding wheel profile with a known groove model and grinding wheel axis setting parameters. Hoang et al. [7] established a general mathematical model for internal-meshing honing for screw rotors. Furthermore, the proposed mathematical model has been verified to honing screw rotors with constant lead and variable lead. Bizzarri and Bartoň [8] proposed a method for machining screw rotors with double-flank milling on the five-axis machine tool, and verified the feasibility of this method on several existing screw rotors. While these studies have provided valuable information and useful reference on forming tool design methods, they have not addressed the influence of forming tool mounting parameters on the screw rotor profile errors.

In contrast, the influence of screw rotor forming tool mounting parameters on screw rotor machining profile errors were revealed in another group of studies. Stosic [9-10], for example, proposed a method for calculating the wear amount of a screw rotor forming milling tool, and obtained the influence of the tool wear on the profile error of the screw rotor through the method of transforming the space coordinate system. In this study, considering the tool and the screw rotor have different relative motion speeds at different contact points, the cutting process would result in different tool wear levels. In a subsequent study, Stosic illustrated the influence of installation angle, axial deviation and center distance on the profile error of the screw rotor. Tao et al. [11] proposed a method to evaluate the screw rotor profile error caused by the installation parameter error of forming grinding wheel, including the installation angle error, center distance error and axial displacement error. Both single factor and coupling factors were comprehensively investigated in this method. Zhao et al. [12], who investigated the influence of multiple factors on screw rotor profile error in $\mathrm{CNC}$ precision forming grinding of screw rotor, further proposed a new $\mathrm{CNC}$ grinding wheel segmentation dressing method to improve screw rotor grinding precision and efficiency. Hoang and $\mathrm{Wu}$ [13] established a general coordinate system for simulating the machining of single-thread screw rotor with end milling cutter on a multi-axis $\mathrm{CNC}$ milling machine. The machining accuracy of the rotor can be improved by using different combinations of end mill tool installation parameters or tool profile corrections. They then performed machining experiments or simulation experiments to verify the correctness of the proposed method. 
Current research is focusing on the mechanism of the screw rotor profile error, meanwhile, other researchers have also proposed the compensation method of the screw rotor profile error [14-16]. Representatively, on the basis of studying the generation of profile error of the screw rotor, Liu et al. [17] proposed a profile error compensation method caused by the wear of the forming wheel. This method was realized by adjusting the installation parameters of the forming wheel, which improved the precision forming grinding efficiency. These researchers have attempted to improve the machining accuracy of the screw rotor by controlling the mounting parameters of the forming tool. One the one hand, the reported models are helpful to improve the profile accuracy of the screw rotor to some extent. On the other hand, these models are established based on a common assumption that the forming tool mounting parameters and profile have been pre-determined. Furthermore, the design method of mounting parameters of the screw rotor forming tool has not been well described in the above studies. In order to overcome the problem of interference between tool and rotor profile during machining of concave rotor profile. Zhang and Fong [18] proposed a novel tilt form grinding (TFG) method. By using their proposed mounting parameter setting method and machine arrangement, the undercutting and secondary enveloping can be avoided in grinding the screw rotor of a vacuum pump with concave profile. Deng and Shu [19] used space envelopment theory to design the profile of forming tool, and introduced the design method of mounting parameters. However, this method can only ensure that there is no interference between the forming tool and the screw rotor. Unfortunately, no research has been conducted to correlate the setting parameters with the cutting performance of the forming tool itself. Practical experience shows that reasonable installation parameters can not only reduce the manufacturing cost of the forming tool, but also improve the cutting performance of the forming tool, thereby improving the manufacturing accuracy of the screw rotor and reducing the manufacturing cost.

Accordingly, this paper proposes a method to design mounting parameters of screw rotor forming tools based on their machinability, in order to guarantee that the designed forming tool have excellent cutting performance. First, the design method of forming tool and the associated forming grinding method are introduced, which provides a theoretical basis for subsequent research. Subsequently, a parametric optimization design program is designed to solve the forming tool installation parameters that satisfy the spatial meshing principle, and the cutting performance of the forming tool with various installation parameters was analyzed to obtain the reasonable mounting parameters. Finally, the screw rotor forming grinding experiments were performed, and the experimental results are in good agreement with the theoretical results, which demonstrates the effectiveness of the screw rotor forming tool installation parameter design method proposed in this paper.

\section{Theoretical background}

\subsection{The coordinate system relationship}

To obtain the installation parameter range that satisfies the spatial meshing relationship and forming process requirements, is a prerequisite for the accurate design of screw rotor forming tool profile. To achieve this, the numerical relationship between the coordinate systems of screw rotor and forming tool needs to be established first. The discrete point of the shaft section of the screw rotor is $\left(x_{t}, y_{t}\right)$, and the three-dimensional model representation can be described as:

$$
[X, Y, Z]=\left[x_{t} \cos \theta-y_{t} \sin \theta, x_{t} \sin \theta+y_{t} \cos \theta, p \theta\right]
$$


where $p$ is the screw parameter of the screw rotor determined by $p=\mathrm{S} / 2 \pi$, and $\mathrm{S}$ in the formula represents the lead of the screw rotor.

Point $\left(Z_{c}, R_{t}\right)$ is a point on the cross section of the forming tool shaft, as shown in Fig. 1, the threedimensional structure of the forming tool can be described by the following equation [3]:

$$
\left[X_{c}, Y_{c}, Z_{c}\right]=\left[R_{t} \cos \phi, R_{t} \sin \phi, f\left(R_{t}\right)\right]
$$

where $X_{c}, Y_{c}$, and $Z_{c}$ are the $3 \mathrm{~d}$ model equation of the forming tool; $R_{t}$ is the radius when the width of the forming tool is $Z_{c} ; \phi$ is the angle between $R_{t}$ and the plane $X_{c} O_{c} Z_{c}$; and the $X_{c}$ to $Y_{c}$ direction is defined as the positive direction.

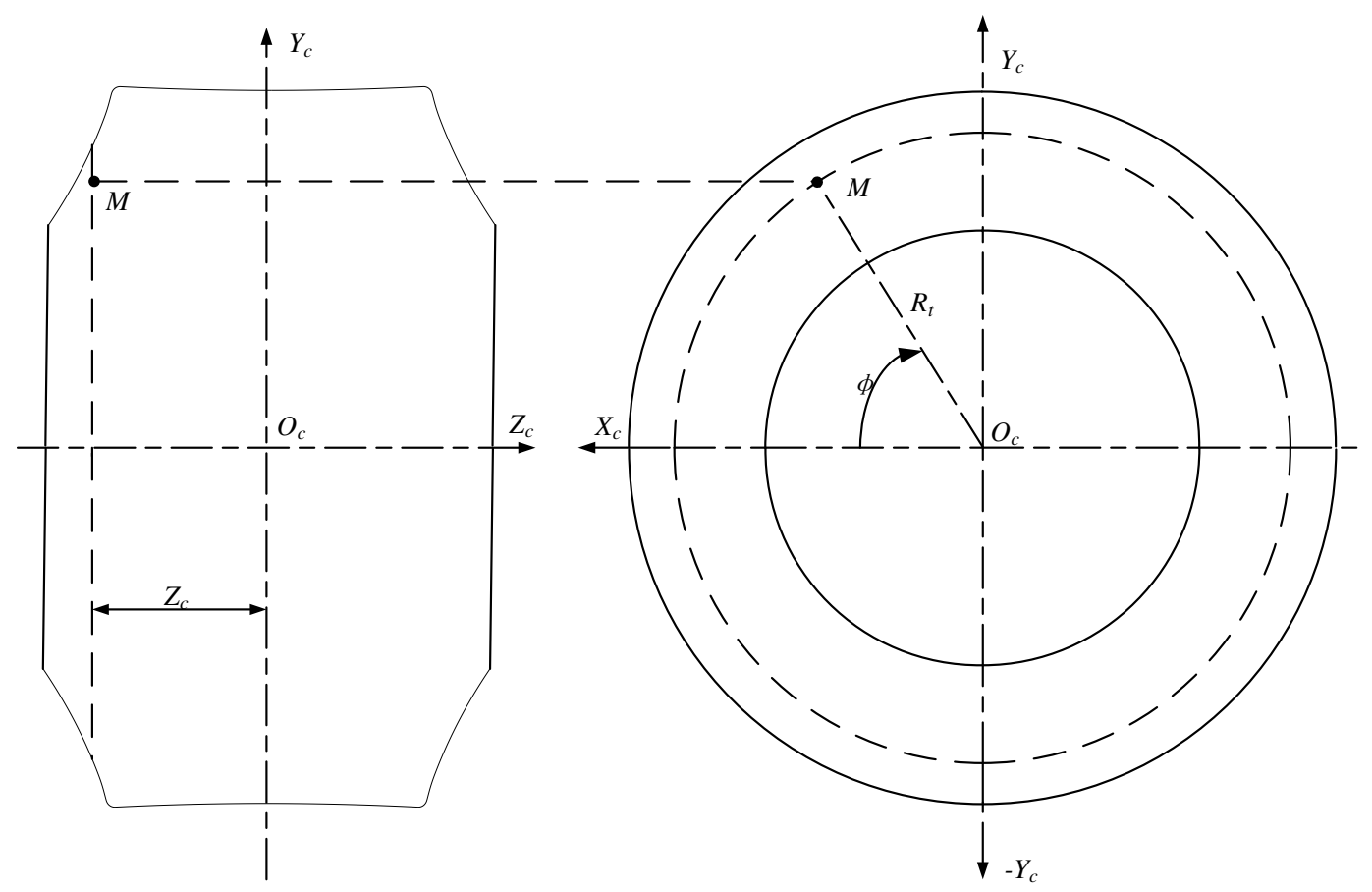

Fig. 1. Forming tool section diagram.

During the forming process, the screw rotor profile is generated through space meshing motion between the forming tool and the screw rotor. The geometric relationship between a screw rotor and a forming tool as shown in Fig. 2 The rotating shafts of the screw rotor and the forming tool are spatially crossed, generating a setting angle $\omega . T$ is called the center distance, which is the distance between the forming tool axis and the screw rotor axis. The point $M$ is a point on the space contact line between the screw rotor and the forming tool. $O-X Y Z$ is the space coordinate system of screw rotor, while $O-$ $X_{c} Y_{c} Z_{c}$ is the space coordinate system of forming tool.

The mutual transformation relationship between the space coordinate system $O-X_{c} Y_{c} Z_{c}$ of the forming tool and the space coordinate system $O-X Y Z$ of the screw rotor is as follows:

$$
\begin{array}{r}
{[X, Y, Y]=\left[X_{c} \cos \omega+Z_{c} \sin \omega, Y_{c}+T, Z_{c} \cos \omega-X_{c} \sin \omega\right]} \\
{[\vec{i}, \vec{j}, \vec{k}]=\left[\cos \omega \overrightarrow{i_{c}}+\sin \omega \overrightarrow{k_{c}}, \overrightarrow{j_{c}}, \cos \omega \overrightarrow{k_{c}}-\sin \omega \overrightarrow{i_{c}}\right]} \\
{\left[X_{c}, Y_{c}, Z_{c}\right]=[X \cos \omega-Z \sin \omega, Y-T, X \sin \omega+Z \cos \omega]} \\
{\left[\vec{i}_{c}, \vec{j}_{c^{\prime}}, \overrightarrow{k_{c}}\right]=[\cos \omega \vec{i}-\sin \omega \vec{k}, \vec{j}, \cos \omega \vec{k}+\sin \omega \vec{i}]}
\end{array}
$$

where $\overrightarrow{i_{c}}, \overrightarrow{j_{c}}, \overrightarrow{k_{c}}$ are the unit vectors in the $X_{c}, Y_{c}$ and $Z_{c}$ directions; $\vec{i}, \vec{j}$, and $\vec{k}$ are the unit vectors in the $X, Y$ and $Z$ directions. 


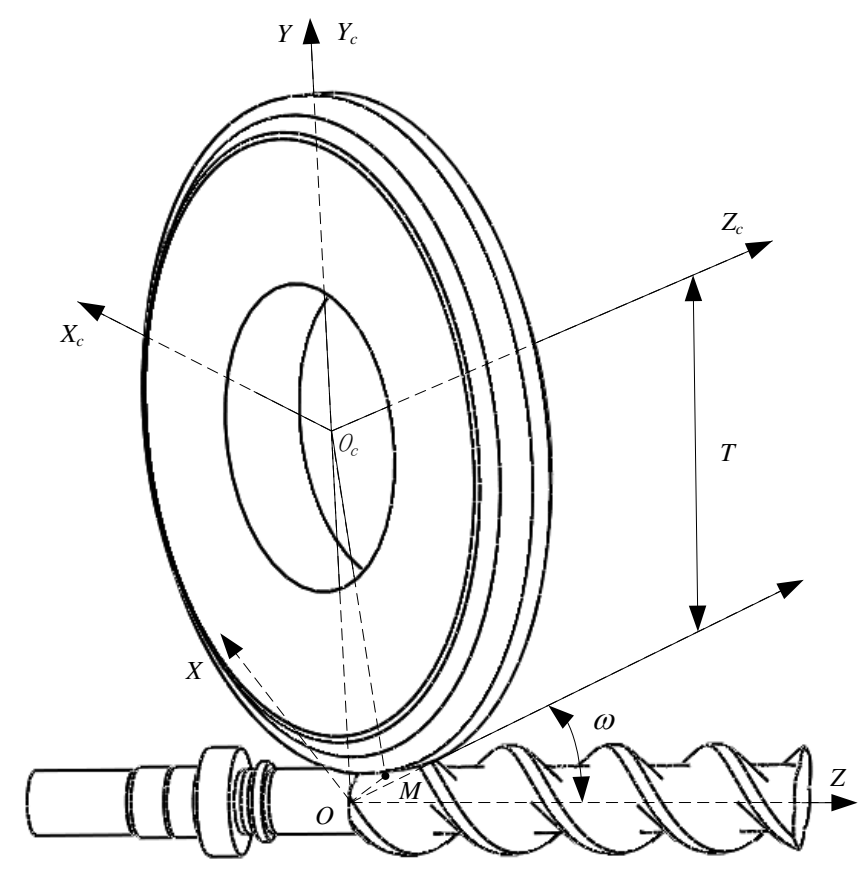

\subsection{Forming tool profile computation model}

When the three-dimensional model equation of the screw rotor is given, the profile equation of the forming tool can be obtained through a series of mathematical operations. The spatial contact line equation between the forming tool and the screw rotor can be expressed by the following equation [3]:

$$
\left(\vec{k}_{c} \times \vec{R}\right) \cdot \vec{n}=0
$$

where $\vec{R}=\overrightarrow{O_{c} M}$ is the radial vector of point $M$ in spatial coordinate system $O-X_{c} Y_{c} Z_{c}$, and $\vec{n}$ is the normal vector at point $M$ in spatial coordinate system $O-X Y Z$. The normal vector $\vec{n}$ in spatial coordinate system $O-X Y Z$ can be solved from the following equation:

$$
\vec{n}=\frac{\partial \vec{r}}{\partial t} \times \frac{\partial \vec{r}}{\partial \theta}=\left|\begin{array}{ccc}
\vec{i} & \vec{j} & \vec{k} \\
\frac{\partial X}{\partial t} & \frac{\partial Y}{\partial t} & \frac{\partial Z}{\partial t} \\
\frac{\partial X}{\partial \theta} & \frac{\partial Y}{\partial \theta} & \frac{\partial Z}{\partial \theta}
\end{array}\right|
$$

By taking the partial derivatives of each component in Eq. (1), respectively, $t$ and $\theta$, the following equation can be established:

$$
\begin{gathered}
\left\{\begin{array}{c}
\frac{\partial X}{\partial t}=\frac{d x_{t}}{d t} \cos \theta-\frac{d y_{t}}{d t} \sin \theta \\
\frac{\partial Y}{\partial t}=\frac{d x_{t}}{d t} \sin \theta+\frac{d y_{t}}{d t} \cos \theta \\
\frac{\partial Z}{\partial t}=0
\end{array}\right. \\
\left\{\begin{array}{c}
\frac{\partial X}{\partial \theta}=-x_{t} \sin \theta-y_{t} \cos \theta \\
\frac{\partial Y}{\partial \theta}=x_{t} \cos \theta-y_{t} \sin \theta \\
\frac{\partial Z}{\partial \theta}=p
\end{array}\right.
\end{gathered}
$$

By substituting Eqs. (9) and (10) into Eq. (8), the components of the normal vector $\vec{n}$ can be solved: 


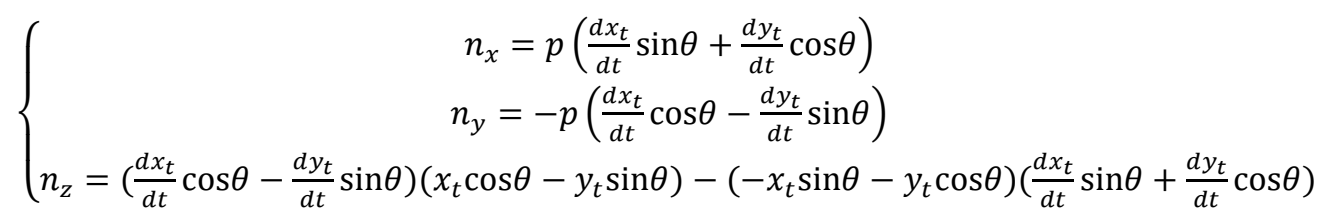

Substituting Eqs. (5), (6) and (11) into Eq. (7) then yields:

$$
\begin{gathered}
{\left[\left(x_{t} \cos \theta-y_{t} \sin \theta\right)(\cos \theta-K \sin \theta)+\left(x_{t} \sin \theta+y_{t} \cos \theta\right)(\sin \theta+K \cos \theta)\right]} \\
{[Y-T-p \cot \omega]+[p(\cos \theta-K \sin \theta)] \cdot p \theta} \\
+[p(\sin \theta+K \cos \theta)] \cdot T \cot \omega=0
\end{gathered}
$$

where $K$ is the first derivative of $y_{t}$ versus $x_{t}$, which can be solved by MATLAB program. As can be seen, angle $\theta$ is the only unknown variable, and it can be solved when $T$, $\omega$, and the profile equation of the screw rotor are given. Thus, the spatial contact line can be deduced, and the profile equation of the forming tool can be solved.

\subsection{Rotor profile computation model}

Similarly, when the three-dimensional model equation of the forming tool is given, the profile equation of the screw rotor can be obtained through a series of mathematical operations. The spatial contact line equation between the screw rotor and the forming tool can be expressed by the following equation [3]:

$$
(\vec{k} \times \vec{r}+p \vec{k}) \cdot \vec{n}=0
$$

where $\vec{r}=\overrightarrow{O M}$ is the radial vector of point $M$ in spatial coordinate system $O-X Y Z$. In the forming tool spatial coordinate system $O-X_{c} Y_{c} Z_{c}$, the vector $\vec{r}$ can be expressed in the following equation:

$$
\vec{r}=\vec{R}+T \overrightarrow{j_{c}}=R_{t} \cos \phi \overrightarrow{i_{c}}+R_{t} \sin \phi \overrightarrow{j_{c}}+f\left(R_{t}\right) \overrightarrow{k_{c}}+T \overrightarrow{j_{c}}
$$

By introducing Eq. (6) into Eq. (14), in the spatial coordinate system $O-X Y Z$ of screw rotor, the vector $\vec{r}$ can be represented as the following equation:

$$
\vec{r}=\left[R_{t} \cos \phi \cos \omega+f\left(R_{t}\right) \sin \omega\right] \vec{i}+\left(R_{t} \sin \phi+T\right) \vec{j}+\left[f\left(R_{t}\right) \cos \omega-R_{t} \cos \phi \sin \omega\right] \vec{k}
$$

The term $\vec{k} \times \vec{r}+p \vec{k}$ can be deduced as follows:

$$
\vec{k} \times \vec{r}+p \vec{k}=\left[R_{t} \cos \phi \cos \omega+f\left(R_{t}\right) \sin \omega\right] \vec{j}-\left(R_{t} \sin \phi+T\right) \vec{i}+p \vec{k}
$$

The normal vector $\stackrel{l}{n}$ can be deduced according the following equation:

$$
\vec{n}=\frac{\partial \vec{r}}{\partial R_{t}} \times \frac{\partial \vec{r}}{\partial \phi}=\left|\begin{array}{ccc}
\vec{i} & \vec{j} & \vec{k} \\
\frac{\partial X}{\partial R_{t}} & \frac{\partial Y}{\partial R_{t}} & \frac{\partial Z}{\partial R_{t}} \\
\frac{\partial X}{\partial \phi} & \frac{\partial Y}{\partial \phi} & \frac{\partial Z}{\partial \phi}
\end{array}\right|
$$

By taking the partial derivative of each item in Eq. (3), respectively, $R_{t}$ and $Z_{c}$, the following equations can be established:

$$
\begin{gathered}
\left\{\begin{array}{c}
\frac{\partial X}{\partial R_{t}}=\cos \phi \cos \omega+f^{\prime}\left(R_{t}\right) \sin \omega \\
\frac{\partial Y}{\partial R_{t}}=\sin \phi \\
\frac{\partial Z}{\partial R_{t}}=f^{\prime}\left(R_{t}\right) \cos \omega-\cos \phi \sin \omega
\end{array}\right. \\
\left\{\begin{array}{c}
\frac{\partial X}{\partial \phi}=-R_{t} \sin \phi \cos \omega \\
\frac{\partial Y}{\partial \phi}=R_{t} \cos \phi \\
\frac{\partial Z}{\partial \phi}=R_{t} \sin \phi \sin \omega
\end{array}\right.
\end{gathered}
$$

By substituting Eqs. (18) and (19) into Eq. (17), the components of the normal vector $\vec{n}$ can be solved:

$$
\left\{\begin{array}{c}
n_{x}=R_{t} \sin \omega-f^{\prime}\left(R_{t}\right) \cos \omega R_{t} \cos \phi \\
n_{y}=-f^{\prime}\left(R_{t}\right) R_{t} \sin \phi \\
n_{z}=R_{t} \cos \omega+f^{\prime}\left(R_{t}\right) \sin \omega R_{t} \cos \phi
\end{array}\right.
$$


Substituting Eqs. (16) and (20) into Eq. (13) then yields:

$$
(T+p \tan \omega) \cos \phi-\left[f\left(R_{t}\right)+\frac{1}{f^{\prime}\left(R_{t}\right)} R_{t}\right] \tan \omega \sin \phi+\frac{1}{f^{\prime}\left(R_{t}\right)}(p-T \tan \omega)=0
$$
where $f^{\prime}\left(R_{t}\right)$ is the first derivative of $Z_{c}$ versus $R_{t}$. Since each $R_{t}$ corresponds to two different values of $Z_{c}$, the $R_{t}$ value can be considered as a function of $Z_{c}$, as shown in Fig. 1. The term $1 / f^{\prime}\left(R_{t}\right)$ is deduced by the derivative rule for inverses:

$$
\frac{1}{f^{\prime}\left(R_{t}\right)}=\left[f^{-1}\left(Z_{c}\right)\right]^{\prime}
$$

Eq. (21) shows that angle $\phi$ is the only unknown variable; angle $\phi$ can be deduced according to $T$, $\omega$, and the profile equation of the forming tool. Thus, the section profile of the screw rotor is further obtained.

\subsection{Profile errors calculation method}

The definition of screw rotor profile error is the basis of studying the influence of mounting parameters on screw rotor profile error. The axial section of screw rotor profile is shown in Fig. 3. By comparing the difference between the processed profile and the theoretical profile, the profile error of the macined profile can be obtained, as shown in Fig. 4 . The coordinates of point $C_{i}$ are denoted by $\left(x_{i}, y_{i}\right)(i=$ $\{1,2, \ldots, m\})$, where $m$ is the number of points determined by the geometric size of the screw rotor and the measuring accuracy of the measuring equipment. In this paper, the minimum distance between the point $C_{i}$ on the machined profile and the initial theoretical profile is defined as the profile error at the point $C_{i}$, which is expressed by $E_{i}$. The profile error $E_{i}$ is negative when point $C_{i}$ is inside the theoretical profile, and vice versa.

In order to facilitate the calculation of the profile error, the theoretical profile of the rotor can be fitted by cubic parameter splines by MATLAB software as follows:

$$
y=S(x)
$$

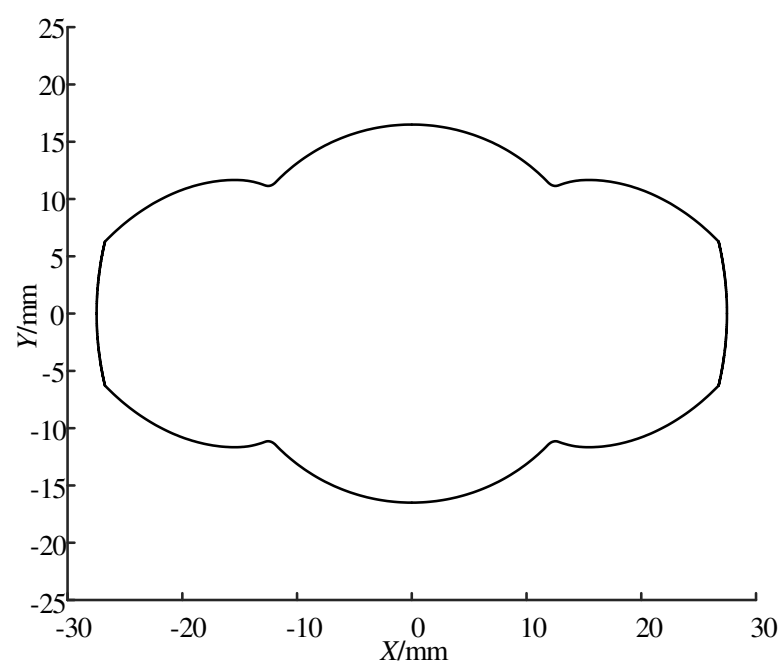

Fig. 3. Theoretical profile of screw rotor. 


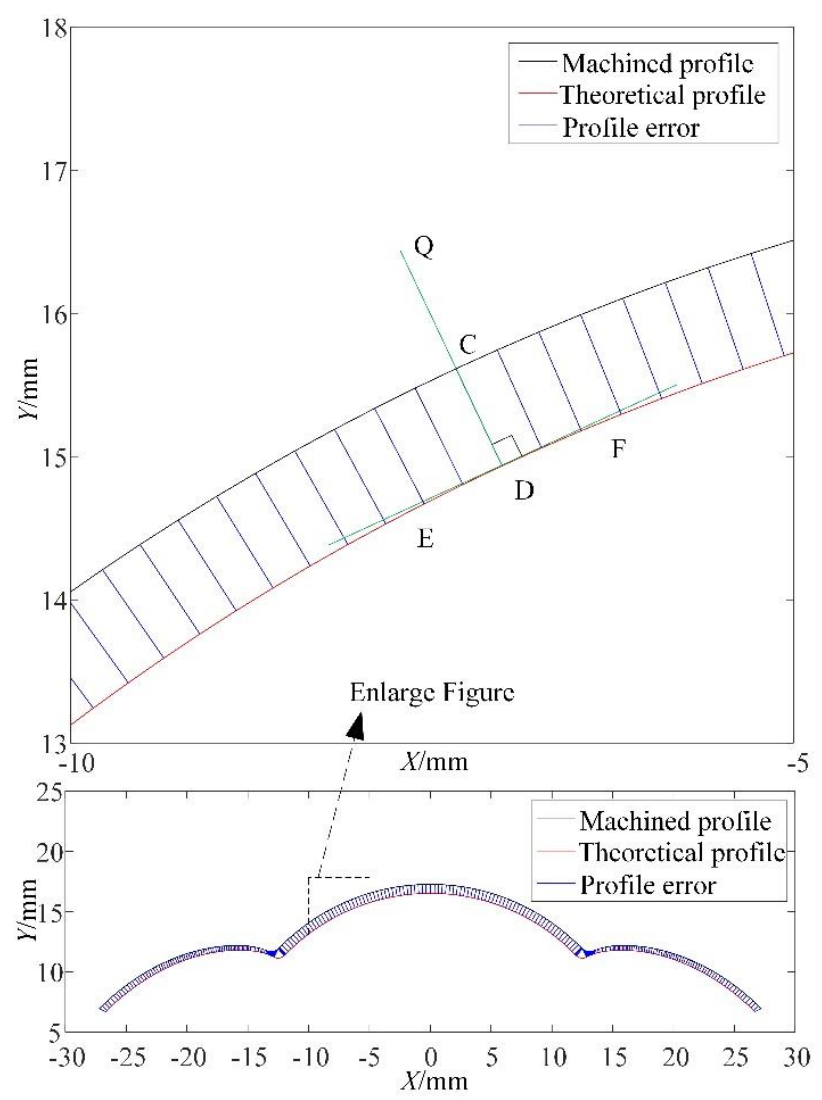

Fig. 4. Schematic diagram of profile error.

The profile error of point $C_{i}$ on the machining profile can be obtained by the following formula:

$$
\begin{gathered}
E_{i}= \pm L_{i}(\min ) \\
L_{i}(\min )=\sqrt{\left(x_{i}-x_{k}\right)^{2}+\left(y_{i}-S\left(x_{k}\right)\right)^{2}}
\end{gathered}
$$

where points $\left(x_{k}, S\left(x_{k}\right)\right)$ satisfy Eq. (23). If $\left(x_{i}{ }^{2}+y_{i}{ }^{2}\right)>\left(x_{k}{ }^{2}+S\left(x_{k}\right)^{2}\right)$, when the machined profile is outside the theoretical profile, "+" is chosen; otherwise, "-" is chosen. The minimum distance, $L_{i}(\mathrm{~min})$, can be easily calculated using MATLAB software; Using this method, the profile error of any point on the machined profile can be accurately obtained.

\section{Mounting parameter optimization decision method}

In the screw rotor precision forming process, the mounting parameters of the forming tool not only determine its own design accuracy but also affect its own cutting performance. In Section 2, The mutual transformation relation between screw rotor and forming tool, and the calculation method of screw rotor profile error have been explained clearly. In view of the importance of mounting parameters to screw rotor forming tool, it is essential to pay attention to the selection strategy of mounting parameters. In this paper, a novel decision method of mounting parameters for screw rotor forming tool based was proposed on the principle of space meshing and the coordinate system mutual transformation between the forming tool and the screw rotor, and the screw rotor precision forming grinding was taken as an example.

\subsection{Mounting angle range optimization decision method}

In order to solve the mounting angle range that meets the process conditions, the mounting angle optimization design program is designed as shown in Fig. 5. During the actual grinding process of the screw rotor, the forming wheel radius becomes smaller and smaller with the increase of grinding time. In order to maximize the use of the abrasive on the forming wheel, the minimum installation center 
distance satisfying the process requirements is taken as the initial center distance parameter. Taking a certain type of male rotor as an example, its geometric parameters are shown in the following Table 1:

Table 1. Geometrical parameters of a female rotor.

\begin{tabular}{ll}
\hline Item & Values \\
\hline Tip diameter $(\mathbf{m m})$ & $54.94-54.95$ \\
Root diameter $(\mathbf{m m})$ & $33.00-33.01$ \\
Lead $(\mathbf{m m})$ & 108.00 \\
Pitch diameter $(\mathbf{m m})$ & 33.00 \\
Lead angle $\left(^{\circ}\right)$ & 46.171 \\
Profile tolerance $(\mathbf{m m})$ & \pm 0.01 \\
Screw direction & Right-handed \\
\hline
\end{tabular}

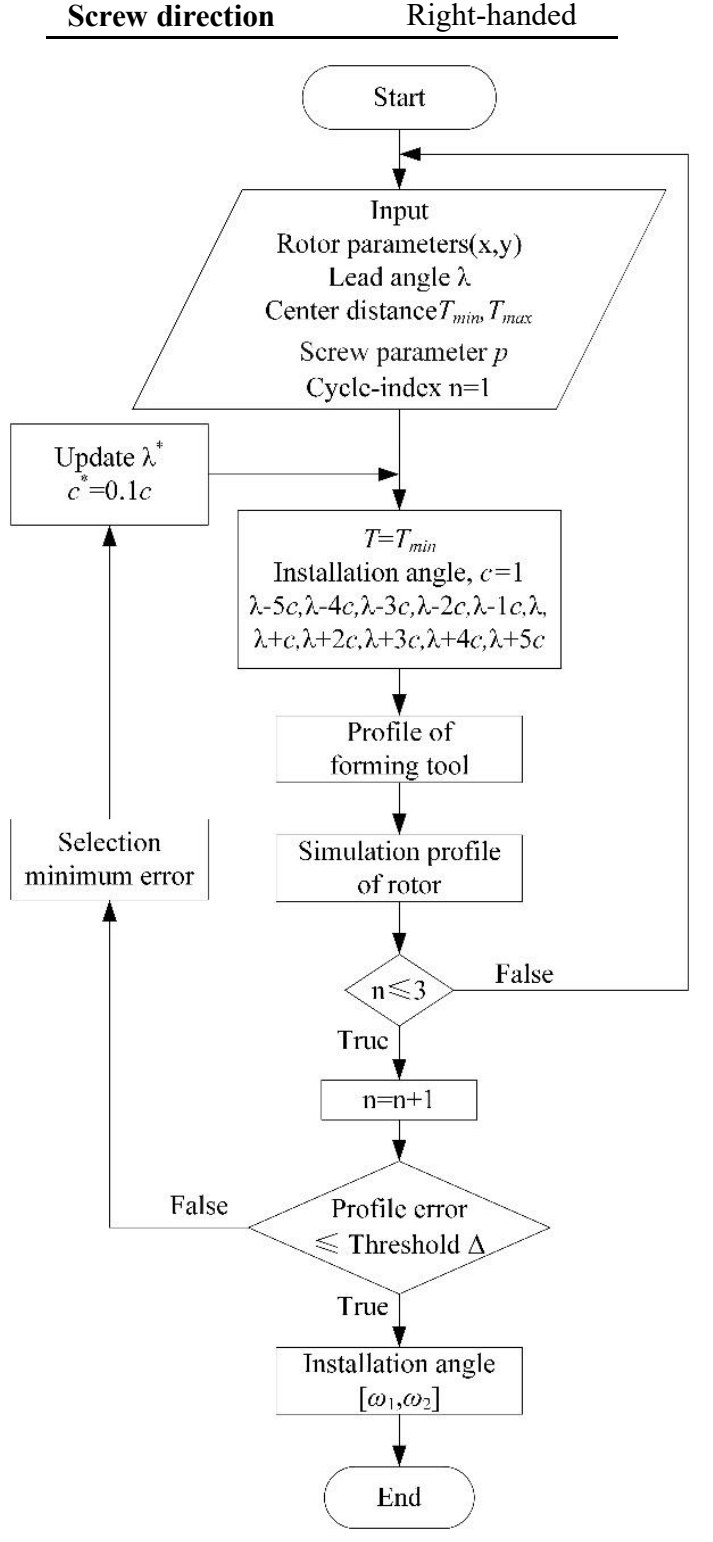

Fig. 5. Flowchart of installation angle optimization design.

The steps of the program for optimization of grinding wheel installation angle of screw rotor are as follows:

- Step 1. Input initial parameter, including discrete data points of screw rotor section profile, pitch circle lead angle, screw parameter, center distance, and cycle-index.

- Step 2. Set initial center distance and mounting angle. 
- $\quad$ Step 3. Forming tool profile generation.

- Step 4. Screw rotor simulation profile generation.

- Step 5. If cycle-index $\mathrm{n}$ less than or equal to 3, the next step was executed; otherwise, it returns to the first step.

- Step 6. The profile error of simulation profile of screw rotor was evaluated. When the maximum value of the profile error $\leq$ threshold $\Delta$, the current mounting angle value would be recorded; otherwise, return to step 2.

In the initial parameter setting, the range of the installation angle is limited to $[\lambda-5, \lambda+5]$, and the judgment condition is set as $E_{i \max } \leq \Delta$. Through three cycles of optimization calculations, the precise mounting angle range that satisfies the conditions can be obtained.

\subsection{Center distance range optimization decision method}

Similarly, in order to solve the center distance range that meets the process conditions, the center distance optimization design program is designed as shown in Fig. 5. In the actual screw rotor grinding process, the installation center distance is usually determined by the structure of the grinding machine and the size of the forming grinding wheel. Therefore, center distance should be searched within the interval $\left[T_{\min }, T_{\max }\right]$. satisfying the structural parameters of machine tool and cutting tool.

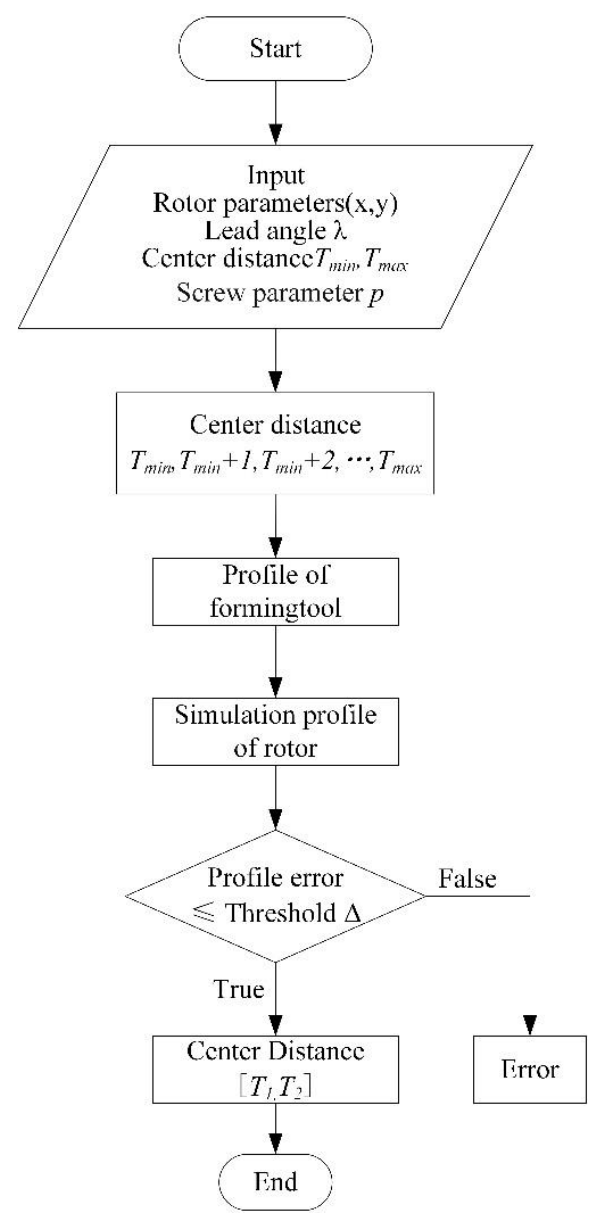

Fig. 6. Flowchart of center distance optimization design.

The steps of the program for optimization of grinding wheel installation center distance of screw rotor are as follows:

- Step 1. Input initial parameter, including discrete data points of screw rotor section profile, pitch circle lead angle, center distance, and screw parameter. 
- Step 2. Set initial center distance and mounting angle.

- Step 3. Forming tool profile generation

- Step 4. Screw rotor simulation profile generation

- Step 5. The profile error of simulation profile of screw rotor was evaluated. When the maximum value of the profile error $\leq$ threshold $\Delta$, the current mounting angle was recorded; otherwise, otherwise, prompt an error and end the program.

The mounting angle and center distance of the forming tool before the screw rotor forming process can be optimized by the method mentioned in this paper. The mounting parameters of the forming tool of the female screw rotor mentioned in Table 1 are shown in Fig. 7.

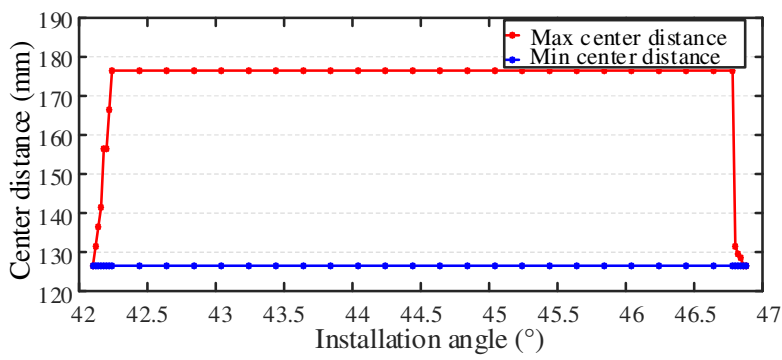

Fig. 7. Mounting parameters range of forming tool.

\subsection{Profile characteristics analysis of forming tool}

At any moment when the rotary surface of the forming tool moves relative to the screw surface of the screw rotor, there is always a tangent contact line between the two surfaces, as shown in Fig. 8, which is the most essential feature of forming grinding. In the process of screw rotor form grinding contact line can be considered to be the actual grinding blade. The forming tool keep axial fixed only around its own axis high-speed rotation. While the screw rotor performs linear and rotary composite motion, which is equivalent to the grinding wheel doing rotary cutting motion along the screw groove of the screw rotor, so as to cut off the excess material of the workpiece.

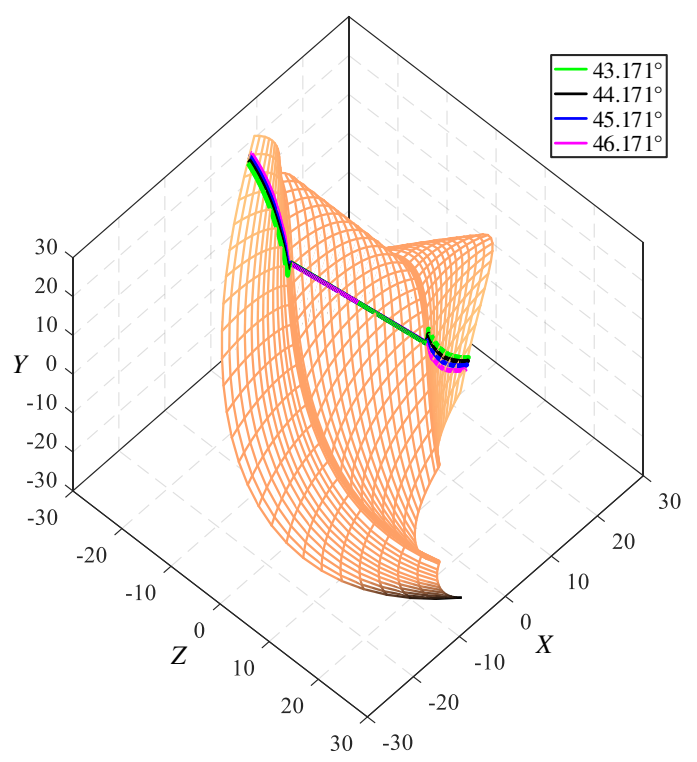

Fig. 8. The shape and pose of space contact line

The forming tool profile is the projection of the contact line on the cross section of the grinding wheel shaft, so it can be seen that the shape and spatial pose of the contact line not only determine the spatial contact relationship between the grinding wheel and the screw rotor, but also determines the profile of 
the grinding wheel. Therefore, the precision grinding quality of screw rotor is closely related to the shape and position of the spatial contact line.

In order to obtain the mounting parameters that match the processing requirements, it is necessary to carry out further in-depth research on the profile characteristics of the forming tool under different mounting parameters. In order to evaluate the cutting performance of the forming tool under different mounting parameters, the cutting performance evaluation system of the forming tool should be established first, as shown in Fig. 9.

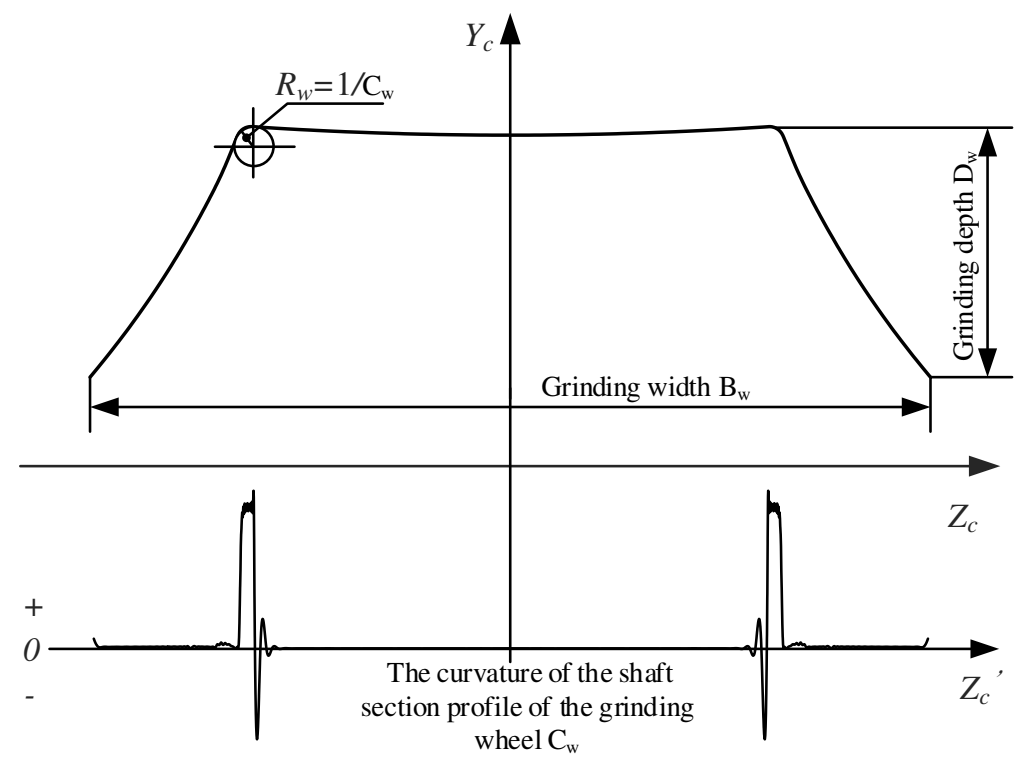

Fig. 9 The evaluation system of forming tool profile
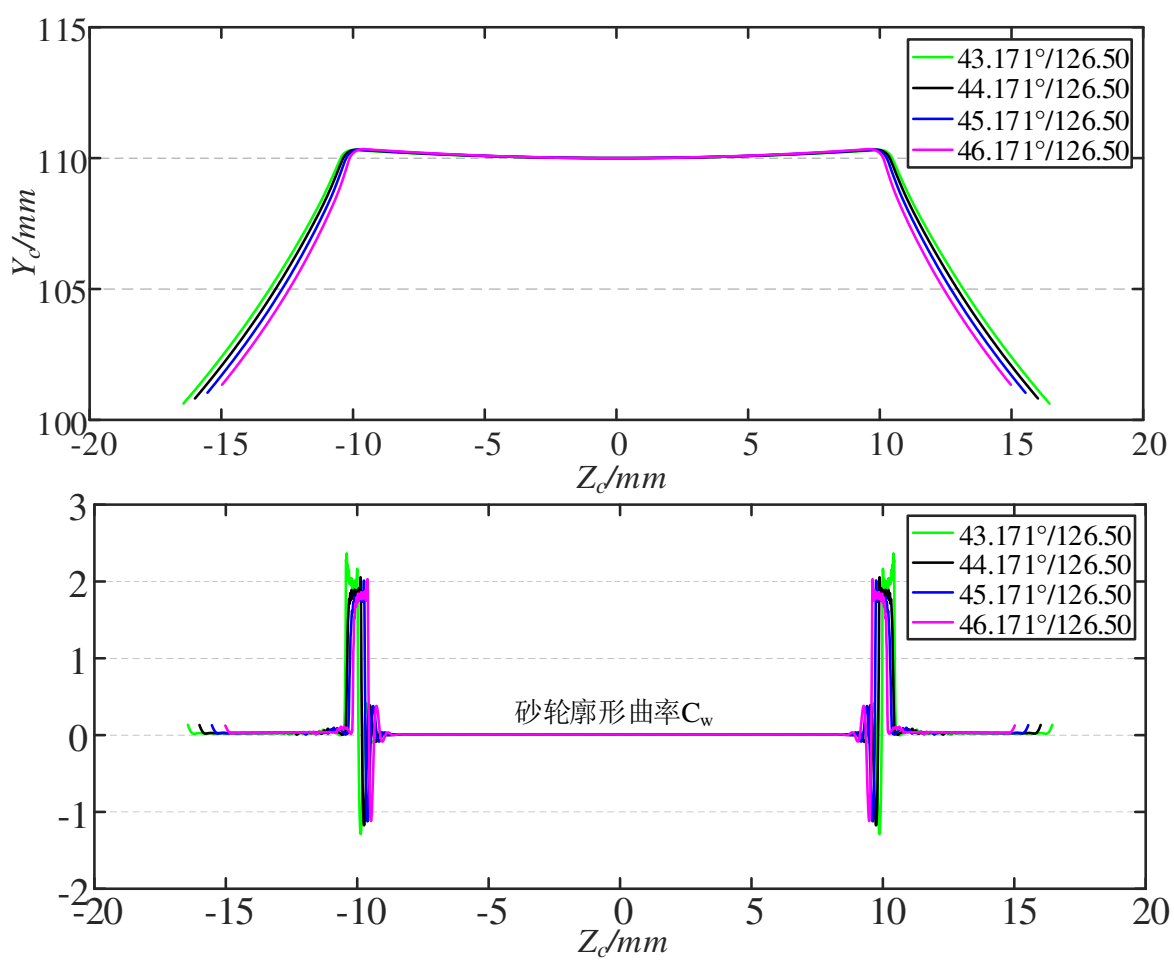

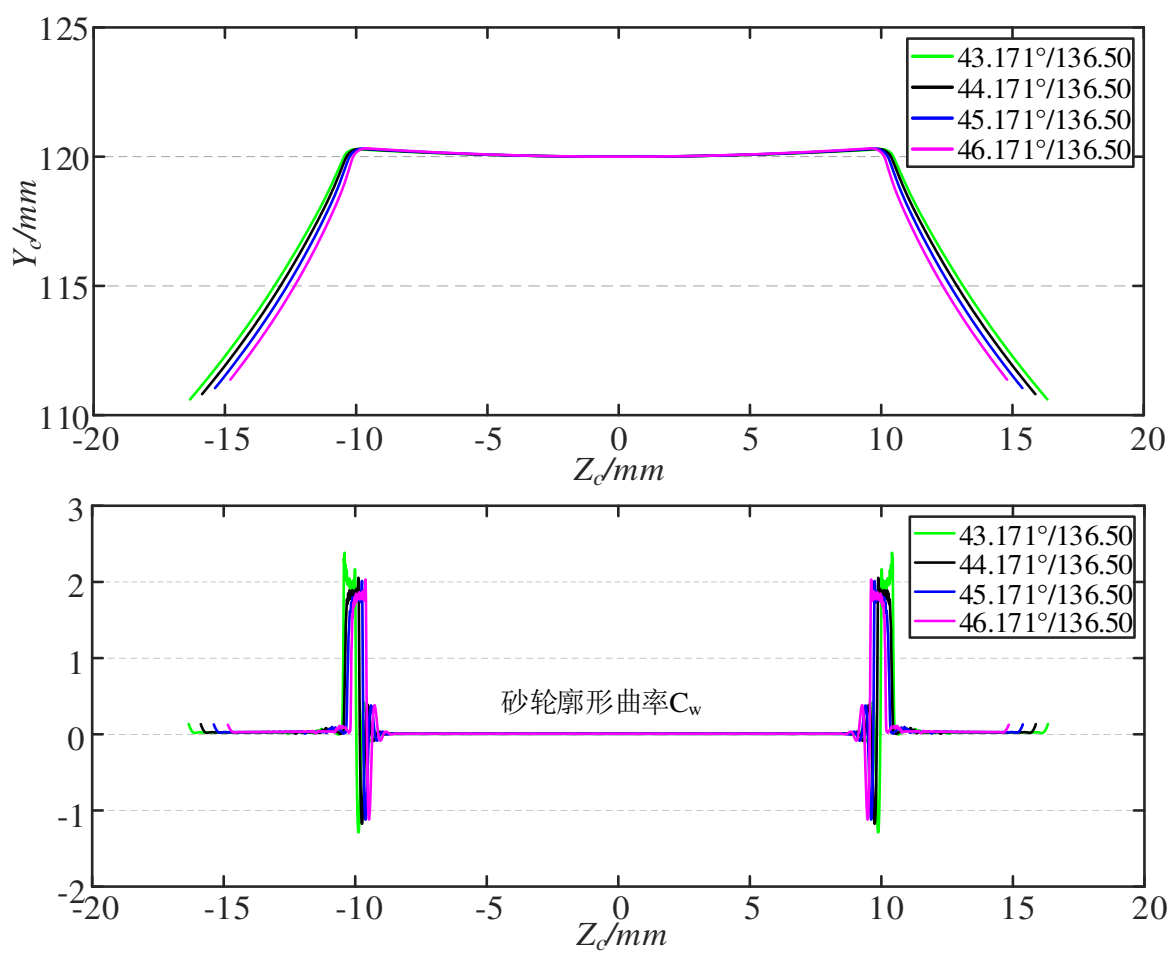

b) Center distance $136.50 \mathrm{~mm}$
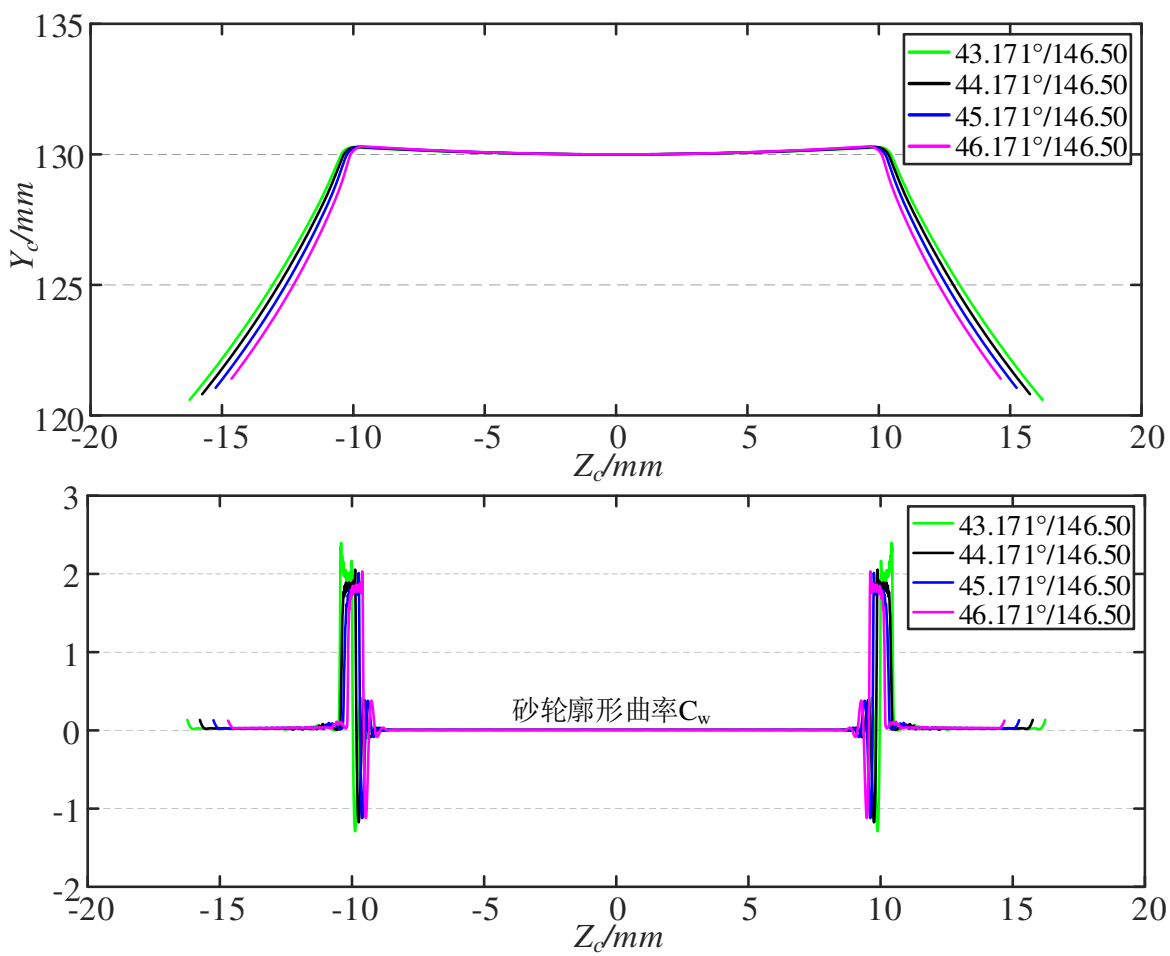

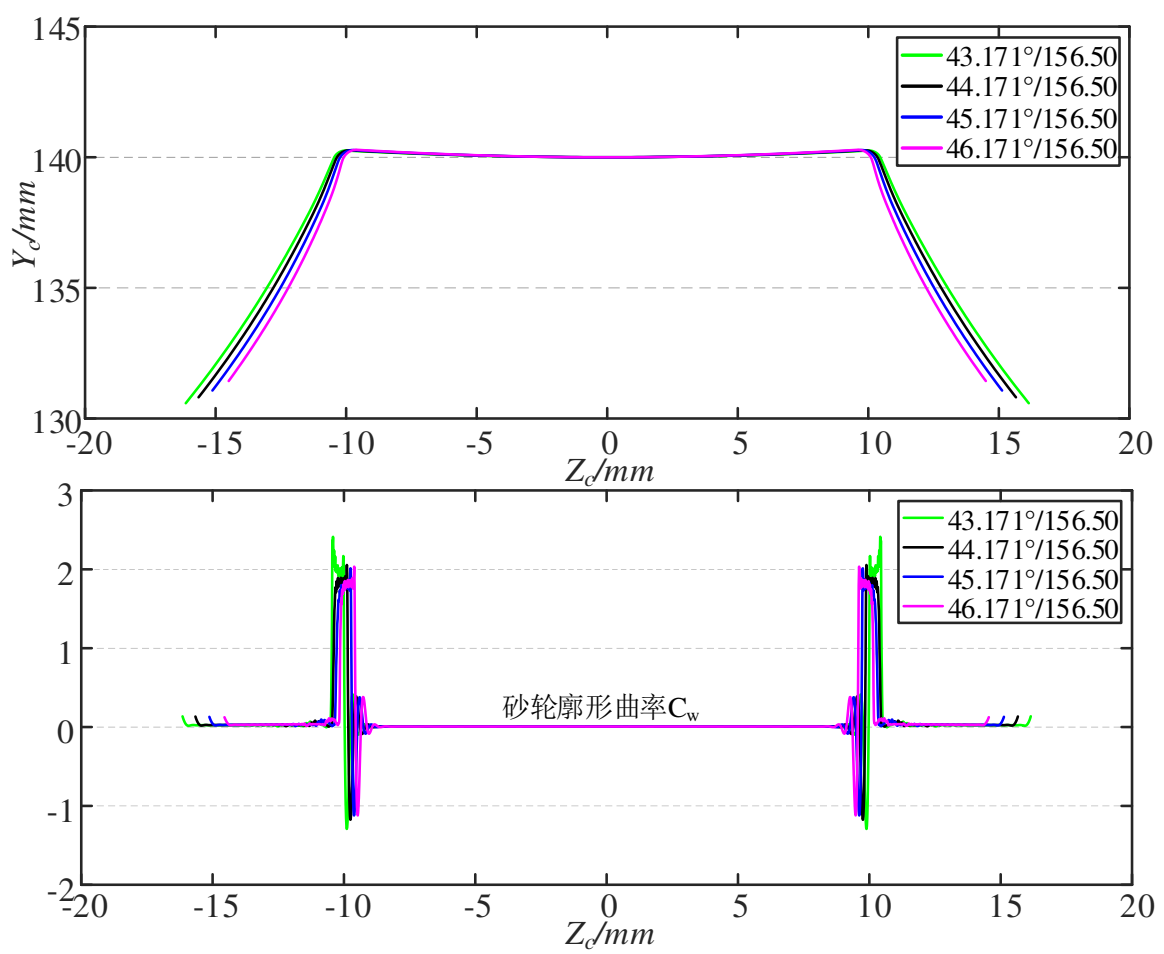

d) Center distance $156.50 \mathrm{~mm}$

319
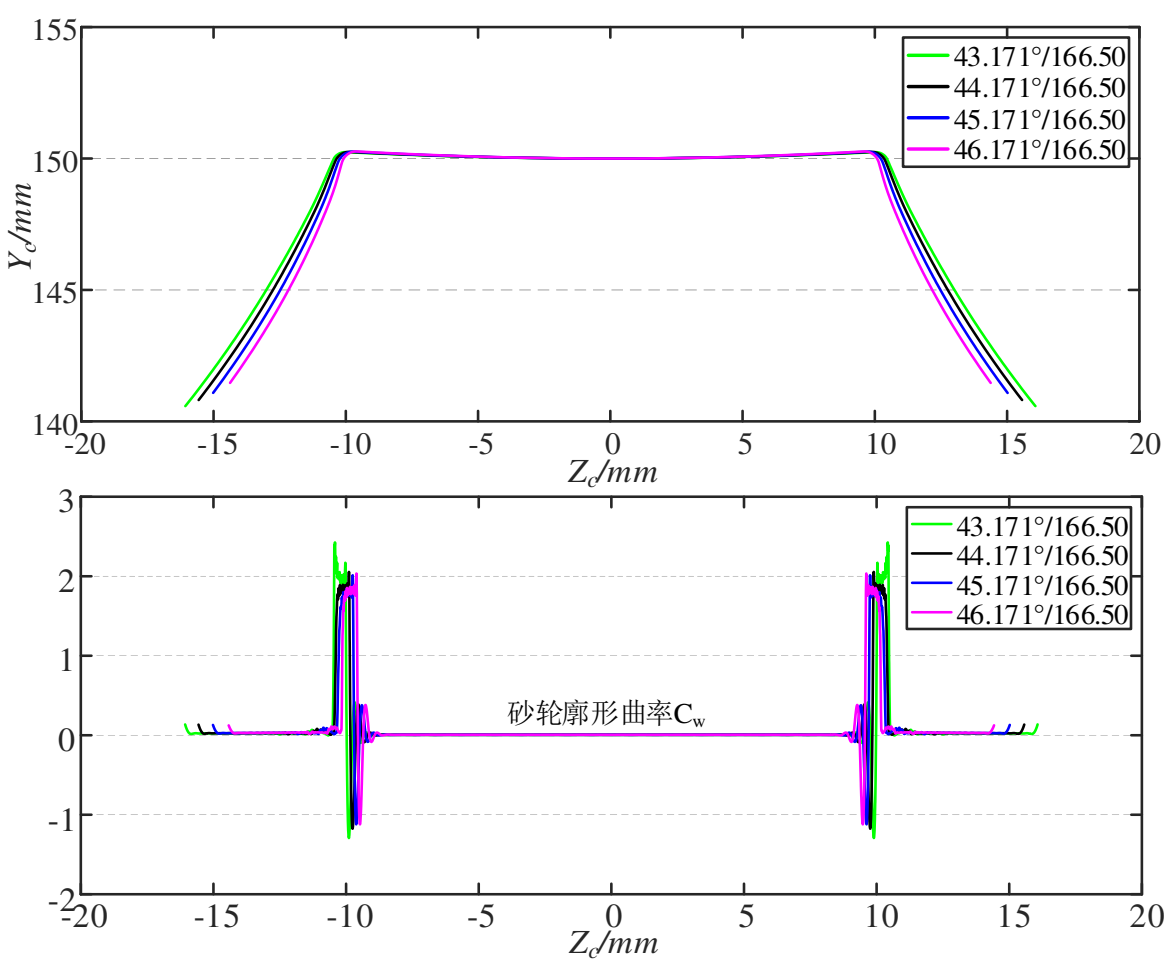

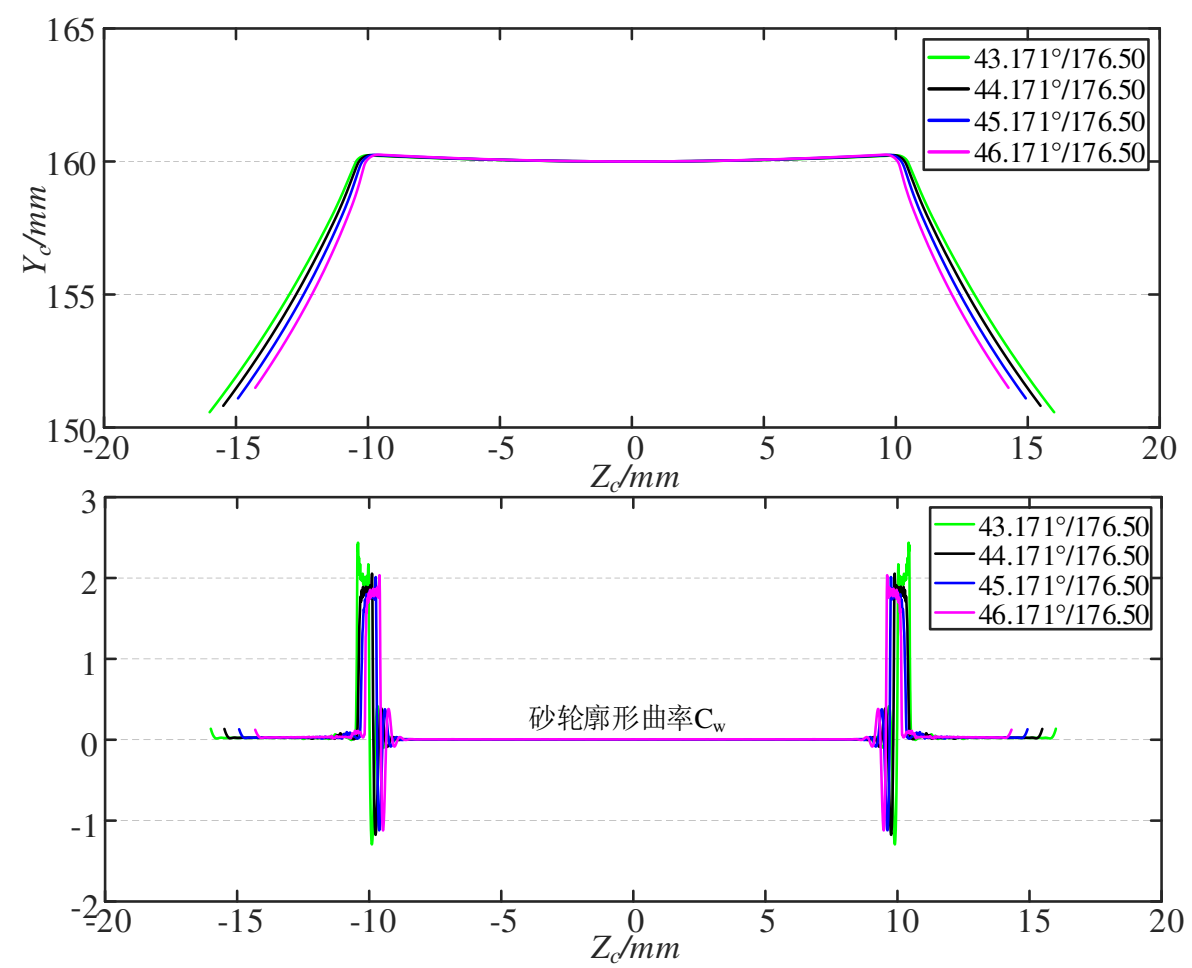

f) Center distance $176.50 \mathrm{~mm}$

Fig.10. Profile characteristics of forming tool

The following information can be derived from Fig. 10. When the center distance between the screw rotor and the forming tool remains constant, the maximum profile curvature of the forming tool decreases slightly with the increase of the mounting angle of the grinding wheel, and the maximum curvature appears at the transition place between the outer circle and the side of the grinding wheel. However, when the mounting angle between the forming tool and the screw rotor remains stable, the profile curvature of the forming tool remains stable even if the center distance between the screw rotor and the formed grinding wheel changes. According to practical experience, the larger the curvature of forming grinding profile, the faster the grinding wheel will wear. In addition, from the perspective of manufacturing, the smaller the curvature of shaped sand profile, the lower the manufacturing cost.

The wear rate k, expressed below as Eq. (23) and defined as the ratio of the grinding wheel wear volume to the material volume removed from the workpiece.

$$
\mathrm{k}=\frac{V_{w}}{V_{S}}=\frac{2 \pi R_{w} \mathrm{~S}_{w}}{L_{S} \mathrm{~S}_{s}}
$$

where $R_{w}, L_{s}$ are respectively the radius of grinding wheel and the length of rotor helix at the contact point between forming tool and workpiece. $S_{w}, S_{s}$ are the wear unit area of grinding wheel and workpiece at their contact point.

When the grinding parameters (grinding speed, cutting depth, cooling conditions, etc.) remain unchanged, $\mathrm{k}$ and $L_{s}$ remain unchanged. Therefore, when the grinding wheel radius $R_{S}$ is smaller, the grinding wheel wear unit area is larger. As a result, the smaller the grinding wheel radius is, the faster the grinding wheel wear will be, and the grinding wheel needs to be dressed more frequently, leading to the reduction of grinding efficiency.

On the other hand, the grinding width of the grinding wheel decreases as the mounting angle increases when the center distance remains unchanged. As can be seen from Fig. 10, when the mounting angle is 
$46.171^{\circ}$, the maximum grinding width of the grinding wheel is $16.1 \mathrm{~mm}$. However, when the mounting angle is $46.171^{\circ}$, the maximum grinding width of the grinding wheel is $13.9 \mathrm{~mm}$, and the corresponding cost of the grinding wheel is saved by more than $13 \%$.

In summary, through the analysis of screw rotor profile characteristics under different mounting parameters, the following conclusions can be known. Different mounting parameters between the screw rotor and the grinding wheel correspond to different profile characteristics of the forming wheel and have different grinding performance. Compared with the center, the mounting angle has a more obvious effect on the profile characteristics of the forming tool. In order to make full use of the grinding wheel, the mounting angle should be determined in priority. Different mounting angle will lead to different width of grinding wheel, so that the screw rotor manufacturing cost is different. When the above factors are taken into account, a smaller mounting angle should be selected to achieve precision form processing of the screw rotor with a lower cost.

\section{Experiment and Results}

\subsection{Experimental setup}

In order to verify the effectiveness and feasibility of the proposed mounting parameter decision method of screw rotor forming grinding wheel, a set of experiments on screw rotor forming grinding were designed. The equipment used in the experiment was shown in Table 4. as shown in Fig. 11. The screw rotor used was Y40Mn (HB 190-210). The screw rotor material in the experiment is Y40Mn in accordance with the actual application, and the hardness is HB170. The mounting parameters of the forming grinding wheel in the experiment are shown in Table 5.

Table 4. Experimental equipment

\begin{tabular}{clll}
\hline No & Setup & Brand & Model \\
\hline $\mathbf{1}$ & Machine tool & Star SU & G 500 H Profile Grinding Machine \\
$\mathbf{2}$ & Grinding wheel & NORTON & 3NQ60-H12VSP \\
$\mathbf{3}$ & Cutting fluid & Variocut & G600HC \\
$\mathbf{4}$ & Measuring equipment & Klingelnberg & P26 \\
\hline
\end{tabular}

Table 5. Mounting parameters

\begin{tabular}{cll}
\hline No & center distance $(\mathrm{mm})$ & mounting angle $\left(^{\circ}\right)$ \\
\hline $\mathbf{1}$ & 176.500 & 43.171 \\
$\mathbf{2}$ & 176.500 & 44.171 \\
$\mathbf{3}$ & 176.500 & 45.171 \\
$\mathbf{4}$ & 176.500 & 46.171 \\
$\mathbf{5}$ & 136.500 & 46.171 \\
$\mathbf{6}$ & 156.500 & 46.171 \\
\hline
\end{tabular}




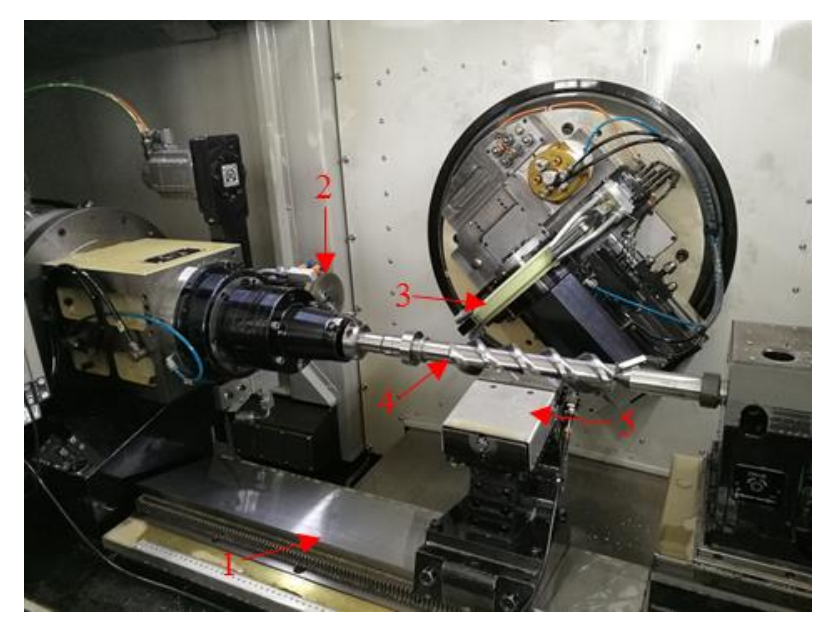

(1) Worktable. (2) Diamond dressing wheel.

(3) Grinding wheel. (4) Screw rotor. (5) Auxiliary supporting

Figure. 10 Grinding experimental setup

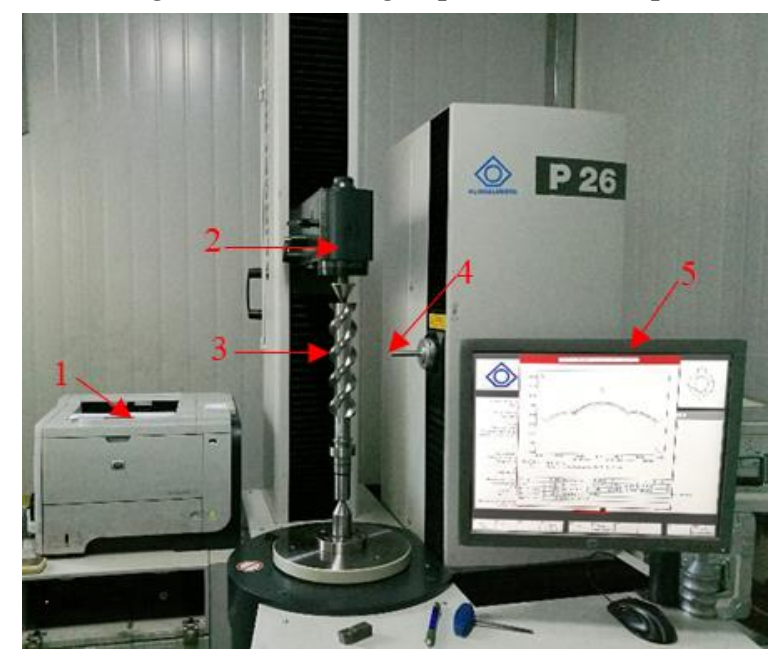

1. Printing mechanism 2. Clamping device 3. Screw rotor 4. Measuring head 5. Display instrument

Fig. 11 The fully automatic CNC-controlled P 26 precision measuring center

\subsection{Results and discussion}

To minimize the effects of grinding wheel wear on the accuracy of experimental results, the grinding wheel was modified before each grinding experiment. The profile error of the screw rotor is measured in the middle position. The results of the six experiments are shown in Appendix, where the actual profile measured from experiment and set theoretical profile are also compared. Compared with the theoretical profile, the error of most positions of each helical groove are within the tolerance band $\pm 0.01 \mathrm{~mm}$. This means that the design method of mounting angle and center distance in this paper is accurate and reliable. In addition, the experimental results show that the error distribution trend of screw rotor is consistent with the slope and curvature distribution trend of forming grinding wheel. The largest error of profile appears at the transition between arc segment (root) and cycloid segment (side), which is also the position with the largest curvature and slope on the forming grinding wheel. It is also observed that as the radius of grinding wheel becomes smaller, the actual machining profile of screw rotor tends to be larger. The reason behind this is fewer abrasive particles will distribute on the surface as the of the radius of grinding wheel gets smaller, thus leading to faster wear of abrasive particles. 
A novel design method for the mounting parameters of screw rotor forming grinding wheel considering the cutting performance of forming grinding wheel was proposed in this paper. The optimum design program of mounting angle and center distance has been developed. Based on the established optimum design program, the range of mounting angle and center distance satisfying the spatial meshing relationship is solved. Furthermore, the profile characteristics (cutting performance) of the grinding wheel under different mounting parameters were investigated. The

\section{Declarations} (cutting performance) of the forming grinding wheel. However, the center distance had little effect on the profile characteristics (cutting performance) of the forming wheel. Nonetheless, when the center distance becomes smaller, the grinding wheel radius becomes smaller, and the grinding wheel wear becomes faster. Grinding experiments for male rotor with different mounting parameters were performed to validate the results of the numerical cases. Some important conclusions are drawn as follows:

(1) A novel model for calculating the mounting parameters of screw rotor forming grinding wheel has been established based on the spatial engagement principle. The range of mounting parameters satisfying the meshing principle and grinding equipment process parameters were obtained

(2) The profile characteristics (cutting performance) of forming grinding wheel under different mounting parameters were investigated. The relationship between the slope, curvature and width of the shaft section profile of the grinding wheel and the mounting parameters of forming grinding wheel were clarified. The mounting angle which has the greatest influence on the profile characteristics of the forming grinding wheel should be controlled in priority.

(3) When pursuing grinding efficiency, a smaller mounting angle should be chosen because a larger grinding wheel width can improve the stability of the grinding system. When pursuing grinding quality and economy, a larger mounting angle should be selected, because a larger mounting angle can reduce the slope and curvature of the grinding wheel profile, while reduce the width of the grinding wheel to save the cost of the grinding wheel.

The above conclusions show that the mounting parameter design method accurate and reliable for screw rotor forming grinding. In this paper, a method based on the cutting performance of the tool is proposed for the design of tool mounting parameters in screw rotor forming machining, which provides a theoretical basis for the selection of unmounted parameters and avoids the unreliability of empirical method. In future work, this optimization design method can be extended and applied to other types of forming processes. This method can also be integrated into the forming machine system to improve the machining quality and efficiency of the machine.

Funding This work was financially supported by The National Key Research and Development Program of China (grant number 2018YFB1701203), the Doctoral Funding of Chongqing University of Chongqing Technology and Business University (grant number 1956029), The opening project of the international joint research center for health care in service of China-Canada equipment system (grant number KFJJ2019061), Scientific research project of Chongqing 
438 Technology and Business University (No. 2152015), Key research platform research team project

439 of Chongqing Technology and Business University (No.ZDPTTD201918)

440 Competing interests The authors declare no competing interests.

441 Availability of data and material The authors confirm that the data supporting the findings of this

442 study are available within the article.

443 Code availability Not applicable.

444 Ethics approval Not applicable.

445 Consent to participate Not applicable.

446 Consent for publication The manuscript is approved by all the authors for publication.

447 Authors' contributions All authors contributed to the study conception and design. Zongmin Liu 448 performed the data analyses and wrote the manuscript. Jirui Wang performed the experiment. Ning

449 Liu contributed significantly to analysis and manuscript preparation. Qian Tang and Bin Xing helped

450 perform the analysis with constructive discussions. All authors read and approved the final 451 manuscript. 


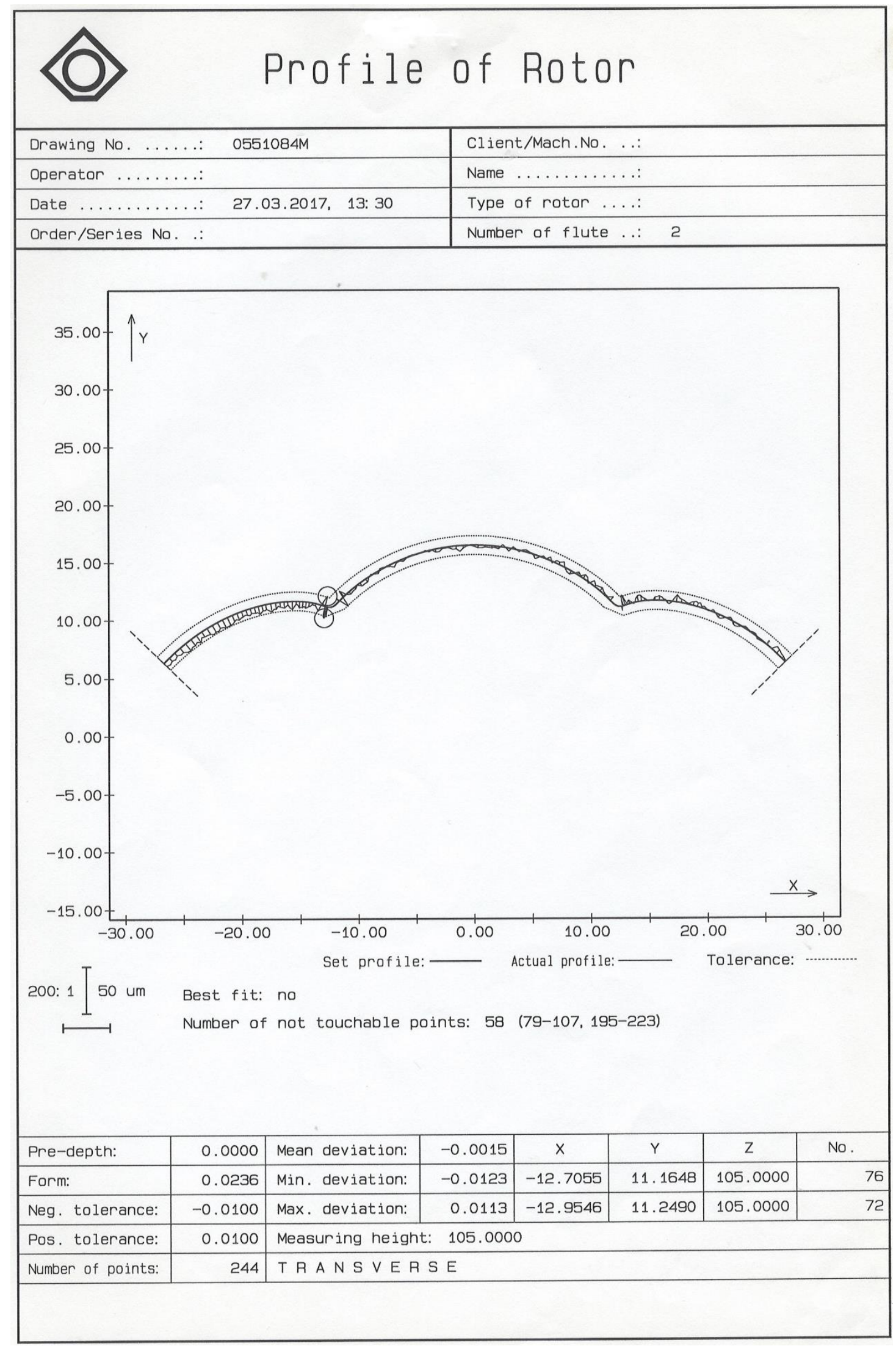




\section{Profile of Rotor}

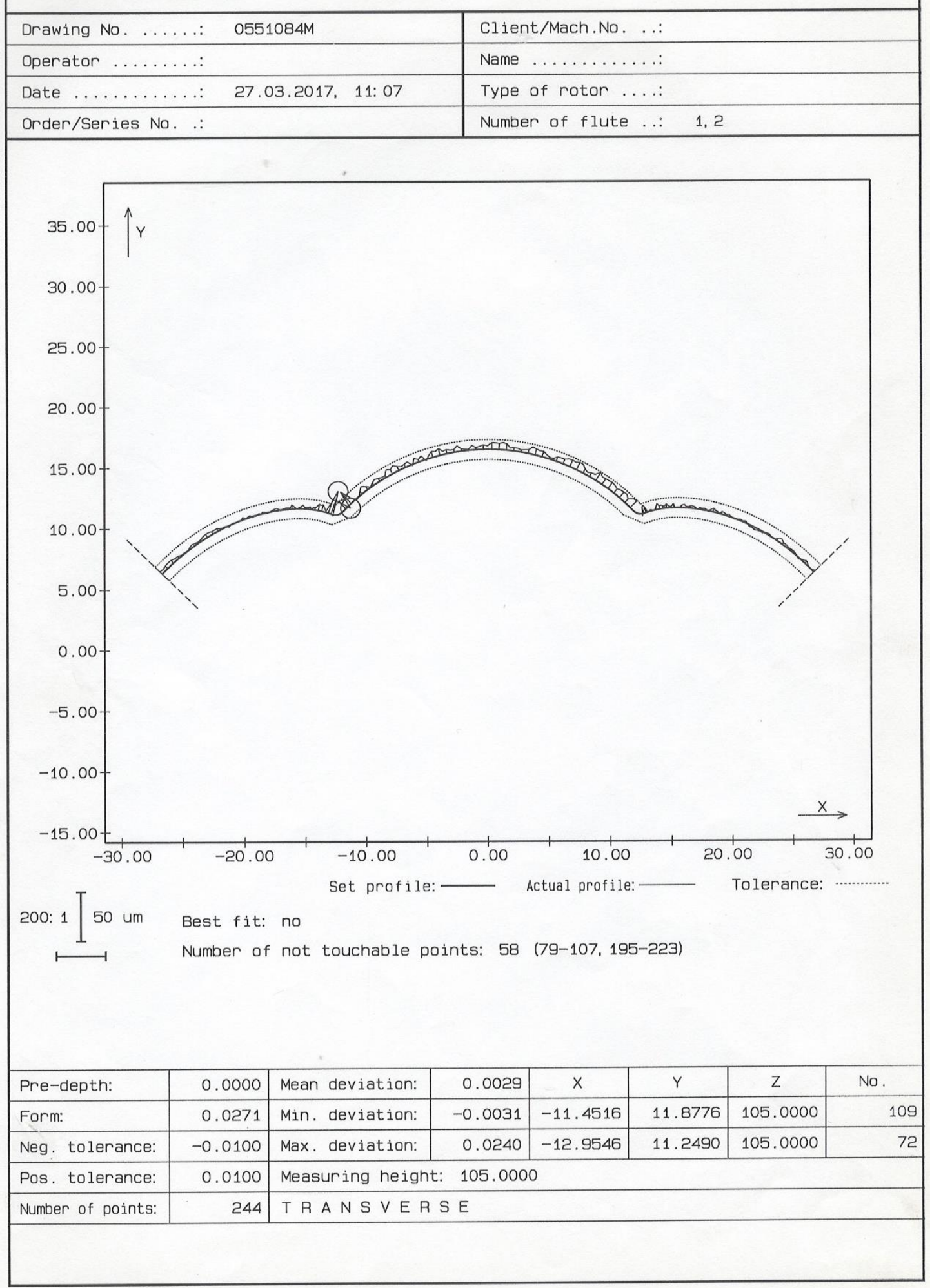

b) Center distance 176.500 , mounting angle 44.171 


\section{Profile of Rotor}

\begin{tabular}{|c|c|c|}
\hline Drawing No. ...... & $0551084 \mathrm{M}$ & Client/Mach.No. ..: \\
\hline Operator ........ & & Name $\ldots \ldots \ldots \ldots$ : \\
\hline Date ........... & $27.03 .2017, \quad 13: 30$ & Type of rotor ....: \\
\hline Order/Series No. .: & & Number of flute $\ldots: \quad 1,2$ \\
\hline
\end{tabular}

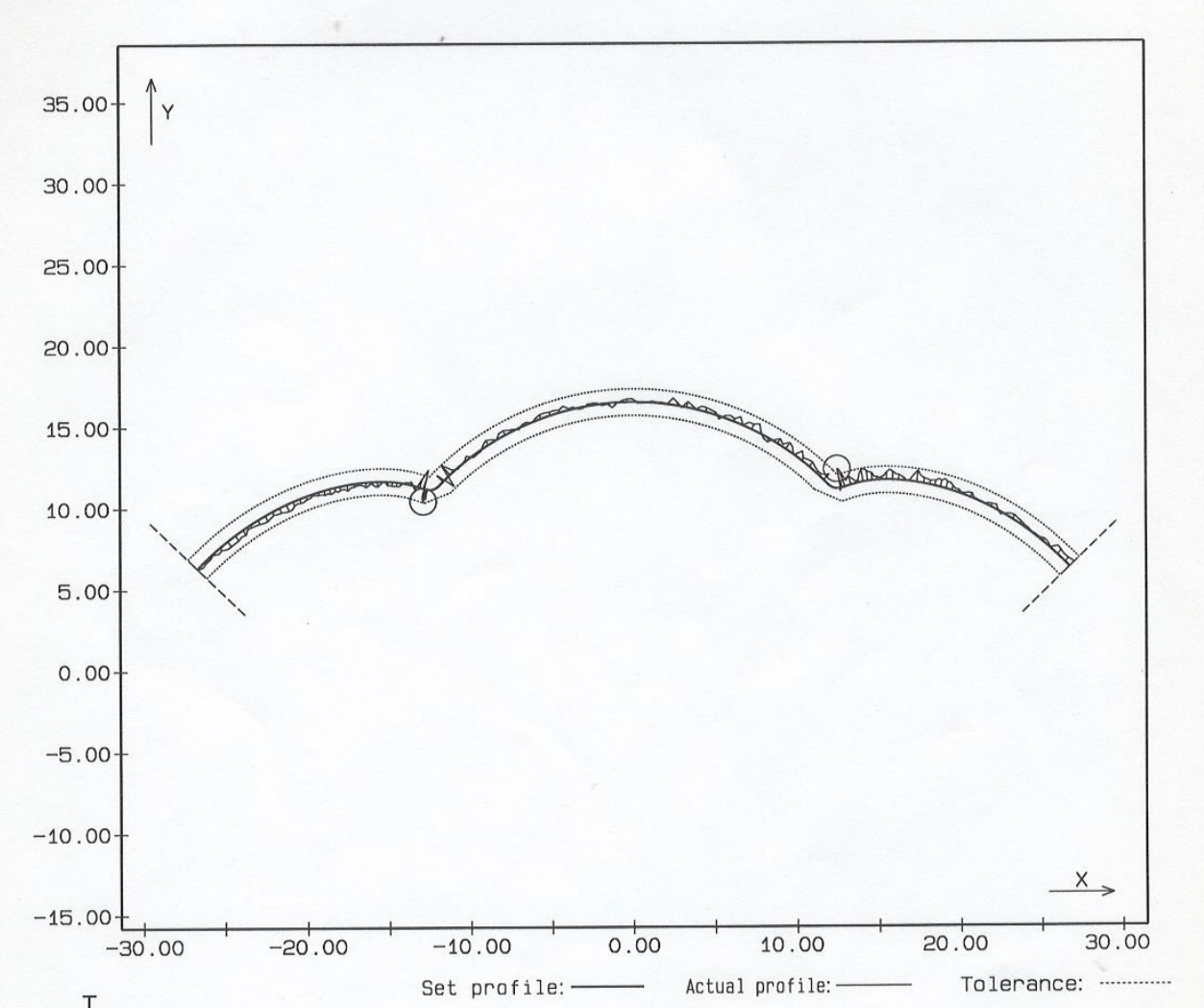

200: 1 [50 um Best fit: no

Set profile: — Actual profile:- Tolerance:

$\stackrel{1}{\longmapsto}$ Number of not touchable points: 58 (79-107, 195-223)

\begin{tabular}{|l|r|l|r|r|r|r|r|}
\hline Pre-depth: & 0.0000 & Mean deviation: & 0.0010 & $X$ & $Y$ & $Z$ & No. \\
\hline Form: & 0.0240 & Min. deviation: & -0.0092 & -12.7055 & 11.1648 & 105.0000 & 76 \\
\hline Neg. tolerance: & -0.0100 & Max. deviation: & 0.0148 & 12.8886 & 11.2259 & 105.0000 & 229 \\
\hline Pos. tolerance: & 0.0100 & Measuring height: 105.0000 & \\
\hline Number of points: & 244 & T R A N S V E R S E & \\
\hline \multicolumn{7}{|l}{} \\
\hline
\end{tabular}




\section{Profile of Rotor}

\begin{tabular}{|c|c|c|}
\hline Drawing No. ...... & $0551084 \mathrm{M}$ & Client/Mach.No. ...: \\
\hline Operator ........ & & Name . . . . . . . . . : \\
\hline Date ........... & $27.03 .2017, \quad 11: 07$ & Type of rotor ....: \\
\hline Order/Series No. .: & & Number of flute ...: 1 \\
\hline
\end{tabular}

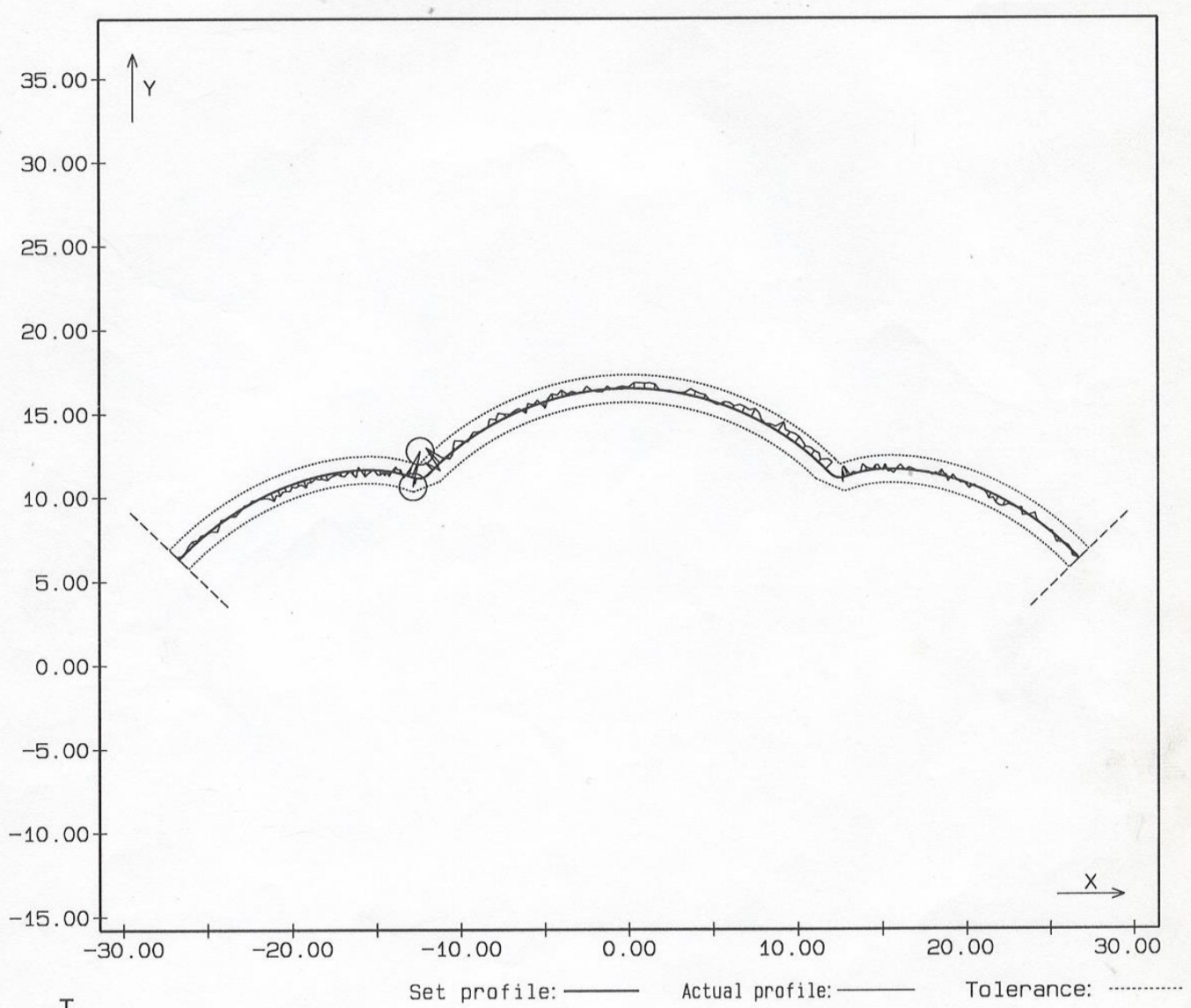

200: 1 I50 um Best fit: no

Number of not touchable points: 58 (79-107, 195-223) 


\section{Profile of Rotor}

\begin{tabular}{|c|c|c|}
\hline Drawing No. ...... & $0551084 M$ & Client/Mach.No. ...: \\
\hline Operator . . . . . & & Name $\ldots \ldots \ldots \ldots$. . . \\
\hline Date $\ldots \ldots \ldots \ldots$. . . & $27.03 .2017, \quad 12: 51$ & Type of rotor ....: \\
\hline Order/Series No. .: & & Number of flute ..: 1 \\
\hline
\end{tabular}

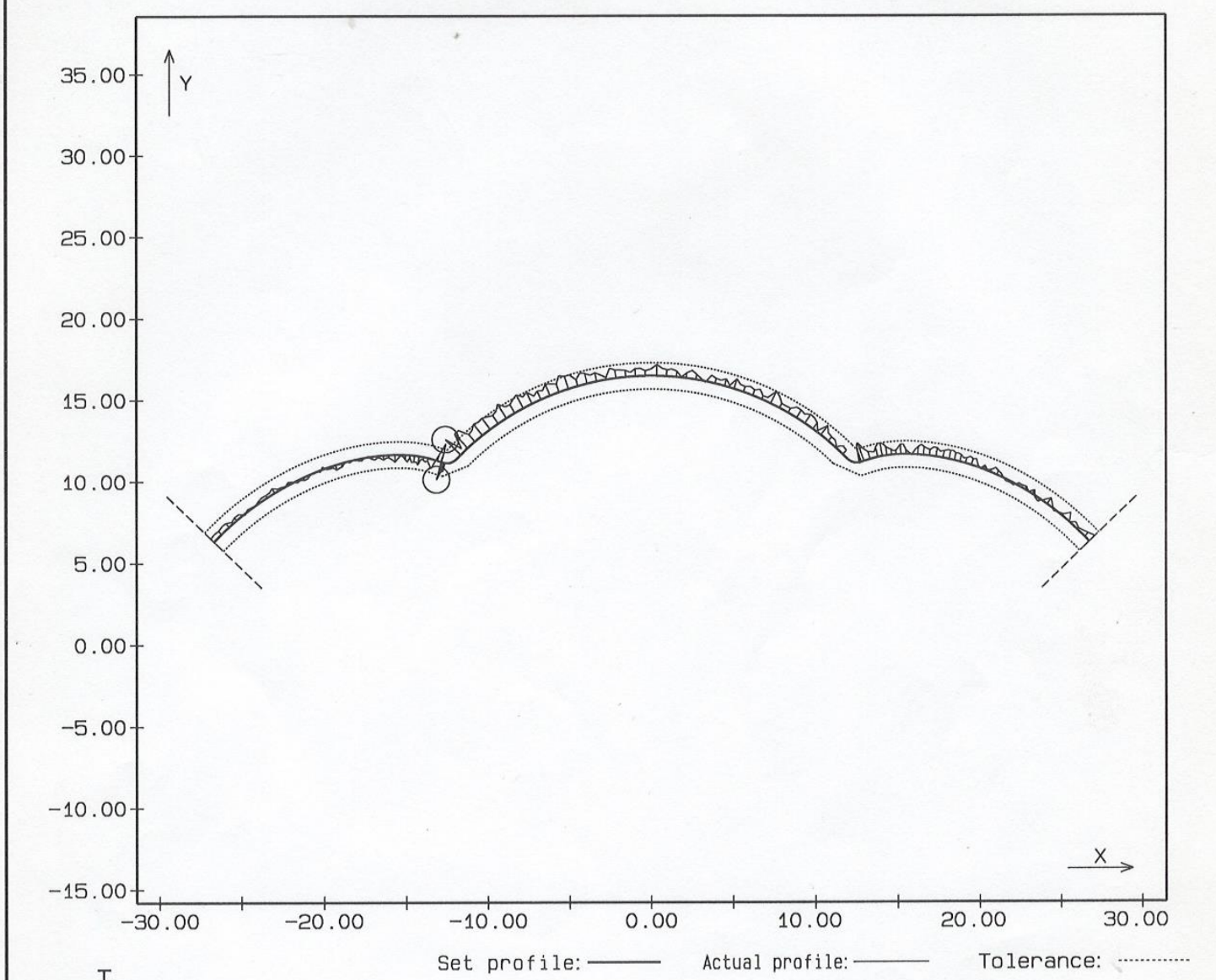

200: $1\left[\begin{array}{ll}50 \text { um } & \text { Set profile: } \\ & \text { Best fit: no } \\ \text { Number of not touchable points: } 58 \text { (79-107, 195-223) }\end{array}\right.$

\begin{tabular}{|c|c|c|c|c|c|c|c|}
\hline Pre-depth: & 0.0000 & Mean deviation: & 0.0033 & $x$ & Y & Z & No. \\
\hline Form: & 0.0301 & Min. deviation: & -0.0137 & -12.7933 & 11. 1922 & 105.0000 & 74 \\
\hline Neg. tolerance: & -0.0100 & Max. deviation: & 0.0165 & -11.6657 & 11.6673 & 105.0000 & 108 \\
\hline Pos. tolerance: & 0.0100 & \multicolumn{6}{|c|}{ Measuring height: 105.0000} \\
\hline Number of points: & 244 & \multicolumn{6}{|c|}{ TR A N S VERSE } \\
\hline
\end{tabular}




\section{Profile of Rotor}

\begin{tabular}{|c|c|c|}
\hline Drawing No. ...... & $0551084 \mathrm{M}$ & Client/Mach.No. ...: \\
\hline Operator ........ & & Name $\ldots \ldots \ldots \ldots$ : \\
\hline Date .......... & $27.03 .2017, \quad 13: 30$ & Type of rotor ....: \\
\hline Order/Series No. .: & & Number of flute ... 1 \\
\hline
\end{tabular}

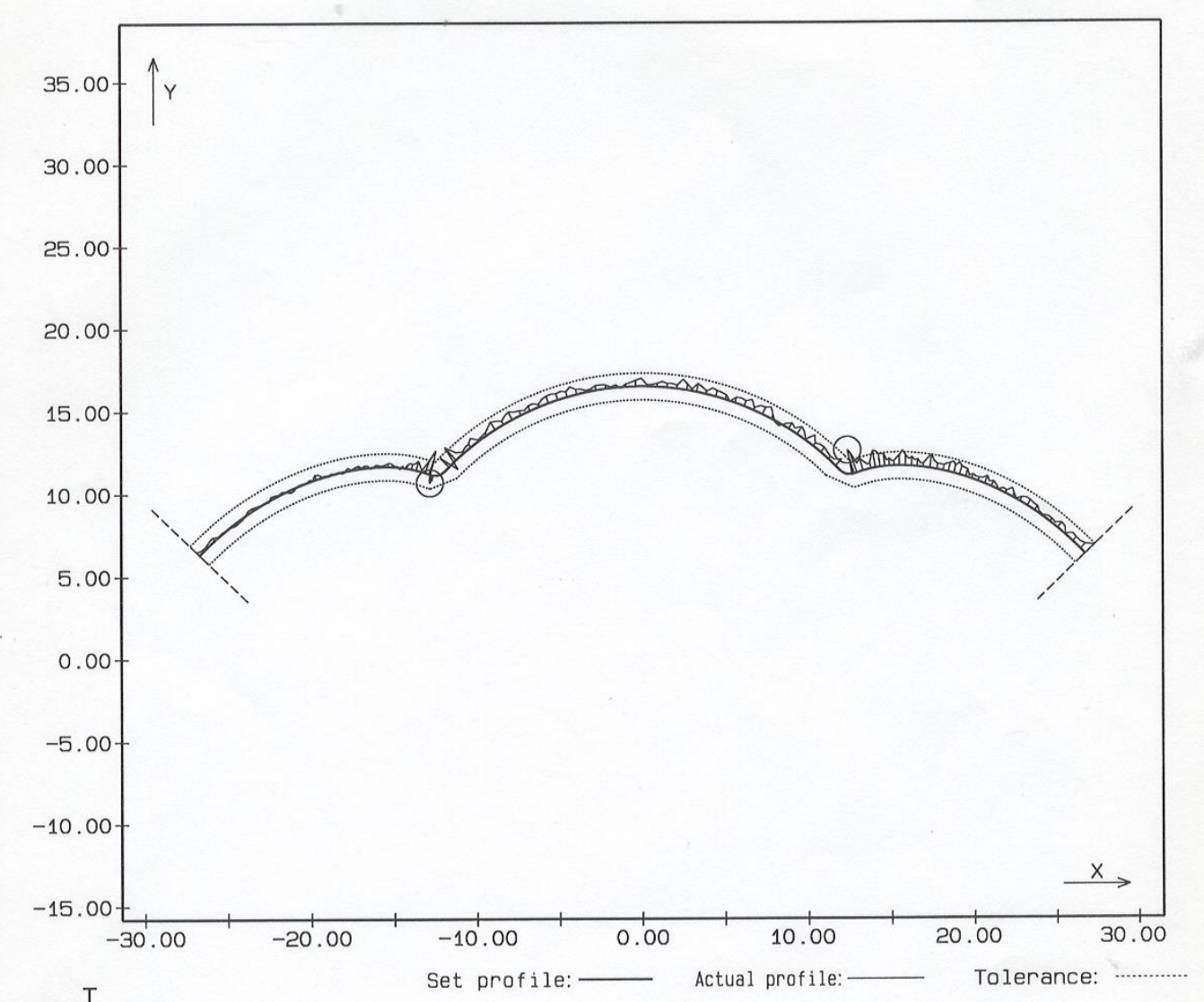

200: 1 T50 um Best fit: no

Number of not touchable points: 58 (79-107. 195-223) 
[1] Kovacevic A, Stosic N, Mujic E, Smith IK (2007) CFD integrated design of screw compressors, Eng. Appl. Comput. Fluid Mech. 1:96-108.

[2] Litvin FL, Fuentes A (2004) Gear geometry and applied theory, Cambridge University Press.

[3] Wu X (2009) Theory of gearing, Xi'an Jiaotong University Press, (in Chinese).

[4] Tang Q, Zhang Y, Jiang Z, Yan D (2015) Design method for screw form cutter based on tooth profile composed of discrete points. J Mech Des 137:085002.

[5] Wu YR, Fong ZH, Zhang ZX (2010) Simulation of a cylindrical form grinding process by the radialray shooting (RRS) method. Mech Mach Theory 45:261-272.

[6] Li G (2017) A new algorithm to solve the grinding wheel profile for end mill groove machining. Int J Adv Manuf Technol 90:775-784.

[7] Hoang MT, Wu YR, Tran VQ (2020) A general mathematical model for screw-rotor honing using an internal-meshing honing machine. Mech Mach Theory 154:104038.

[8] Bizzarri M, Bartoň M (2021) Manufacturing of screw rotors via 5-axis double-flank cnc machining. Comput Aided Des 132:102960.

[9] Stosic N (2006) Evaluating errors in screw rotor machining by tool to rotor transformation. Proc Inst Mech Eng Part B J Eng Manuf 220:1589-1596.

[10] Stosic N (2006) A geometric approach to calculating tool wear in screw rotor machining. Int J Mach Tools Manuf 46:1961-1965.

[11] Tao L, Wang Y, He Y, Feng H, Ou Y, Wang X (2016) A numerical method for evaluating effects of installation errors of grinding wheel on rotor profile in screw rotor grinding. Proc Inst Mech Eng. Part B J Eng Manuf 230:1381-1398.

[12] Zhao, Y, Zhao, S, Wei, W, Hou, H. Precision grinding of screw rotors using CNC method. Int J. Adv Manuf Technol 89:2967-2979.

[13] Hoang MT, Wu YR (2021) Error compensation method for milling single-threaded screw rotors with end mill tools. Mech Mach Theory 157:104170.

[14] Xiang S, Li H, Deng M, Yang J (2018) Geometric error analysis and compensation for multi-axis spiral bevel gears milling machine. Mech Mach Theory 121:59-74.

[15] Ding H, Tang J, Zhong J (2016) Accurate nonlinear modeling and computing of grinding machine settings modification considering spatial geometric errors for hypoid gears. Mech Mach Theory 99:155-175.

[16] Shih YP, Chen SD (2012) A flank correction methodology for a five-axis CNC gear profile grinding machine, Mech Mach Theory 47:31-45.

[17] Liu Z, Tang Q, Liu N, Song J. (2019) A profile error compensation method in precision grinding of screw rotors. Int J. Adv Manuf Technol 100:2557-2567.

[18] Zhang ZX, Fong ZH (2015) A novel tilt form grinding method for the rotor of dry vacuum pump. Mech Mach Theory 90:47-58.

[19] Deng D, Shu P (1982) Rotary Compressor. China Machine Press, (in Chinese). 